Summer 8-21-2019

\title{
Enhancing Quality of Life of People With Visual Impairments Through Aesthetic Techniques
}

Christia M. Labro

University of St. Augustine for Health Sciences

DOI: https://doi.org/10.46409/sr.OGHP2393

Follow this and additional works at: https://soar.usa.edu/capstones

Part of the Medicine and Health Commons, Other Medicine and Health Sciences Commons, Other Public Health Commons, Sociology of Culture Commons, and the Women's Health Commons

\section{Recommended Citation}

Labro, C. M. (2019). Enhancing Quality of Life of People With Visual Impairments Through Aesthetic Techniques. [Doctoral project, University of St Augustine for Health Sciences]. SOAR @ USA: Student Capstone Projects Collection. https://doi.org/10.46409/sr.0GHP2393

This Capstone is brought to you for free and open access by the Student Research at SOAR @ USA. It has been accepted for inclusion in Student Capstone Projects by an authorized administrator of SOAR @ USA. For more information, please contact soar@usa.edu, erobinson@usa.edu. 
ENHANCING QUALITY OF LIFE OF PEOPLE WITH VISUAL IMPAIRMENTS THROUGH AESTHETIC TECHNIQUES

By

Christia M. Labro

A Capstone Project Presented in Partial Fulfillment

of the Requirements for the Degree of DOCTOR OF OCCUPATIONAL THERAPY

University of St. Augustine for Health Sciences

August 19, 2019 


\section{ENHANCING QUALITY OF LIFE OF PEOPLE WITH VISUAL IMPAIRMENTS THROUGH AESTHETIC TECHNIQUES}

By

Christia M. Labro

has been approved

August 19, 2019

APPROVED:

Erin Schwier, EdD, OTD, OTR/L, Program Director

Susan MacDermott, OTD, OTR/L, Doctoral Coordinator

ACCEPTED AND SIGNED

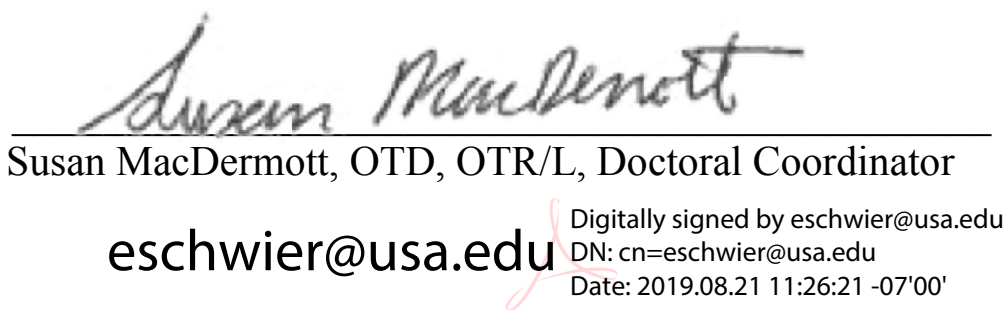

Erin Schwier, EdD, OTD, OTR/L, Program Director 


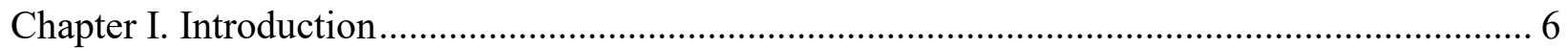

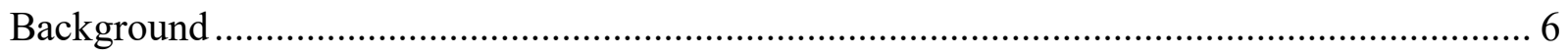

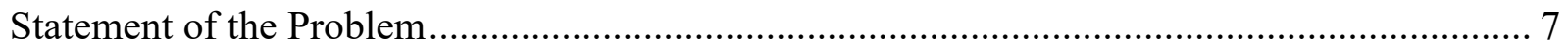

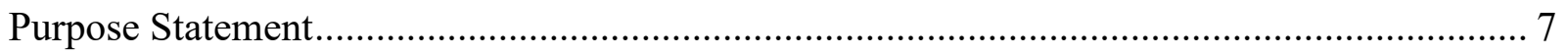

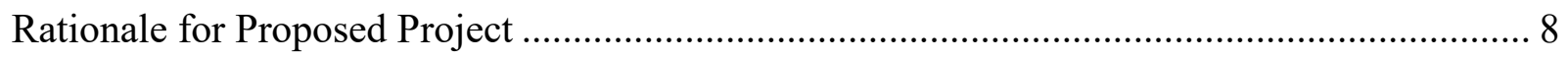

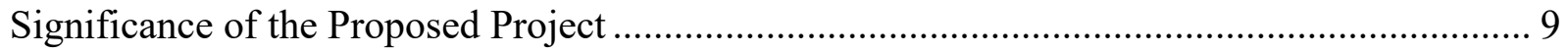

Preliminary Project Objectives ................................................................................... 10

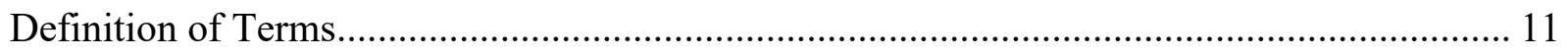

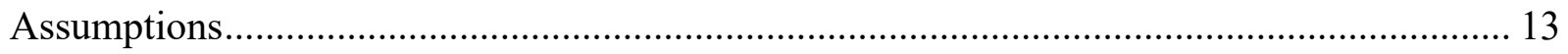

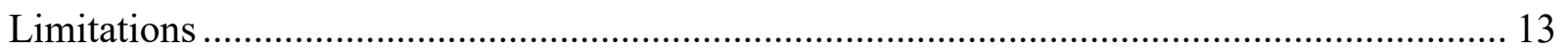

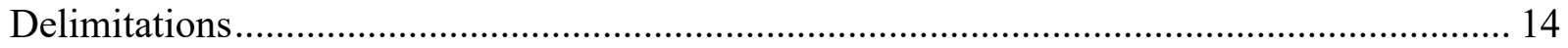

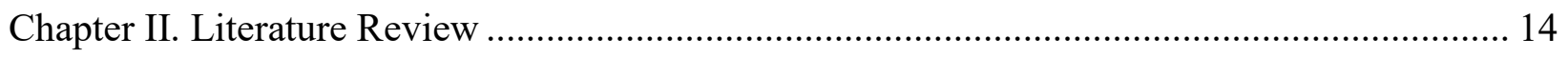

Occupational Therapy Approaches and Interventions ................................................. 14

Psychosocial Factors Associated with Vision Loss ...................................................... 15

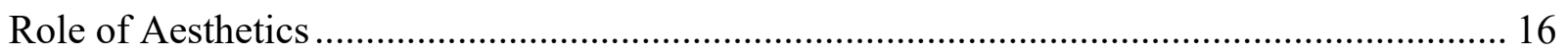

Chapter III. Proposed Methods and Timeline .................................................................. 17

Proposed Project Description and Participants .......................................................... 17

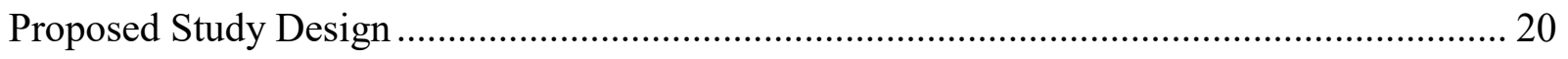


Proposed Analysis

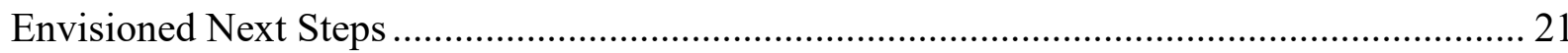

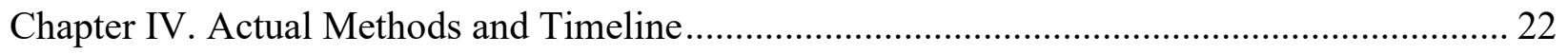

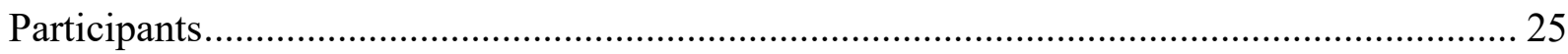

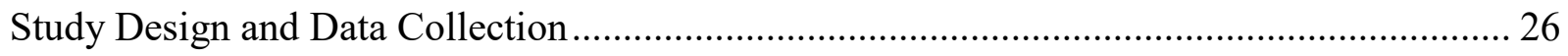

Chapter V. Data Analysis and Results ........................................................................... 27

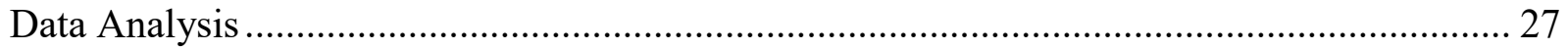

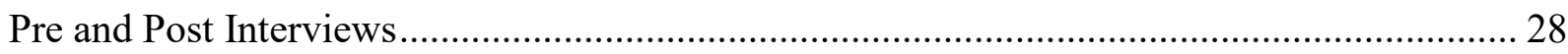

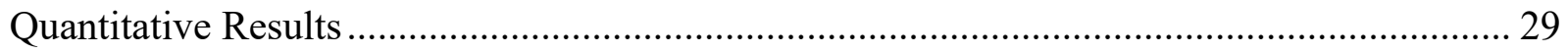

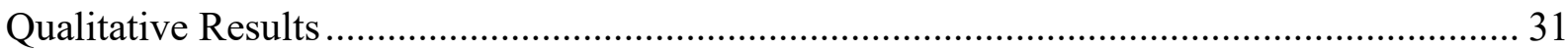

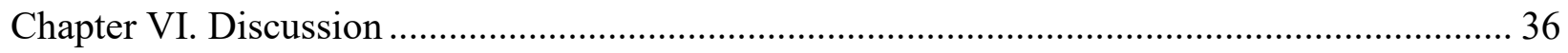

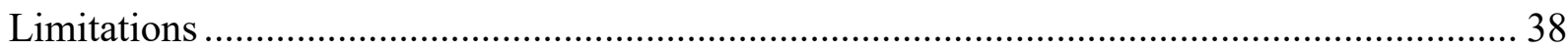

Implications for Occupational Therapy Practice and Future Projects ................................ 40

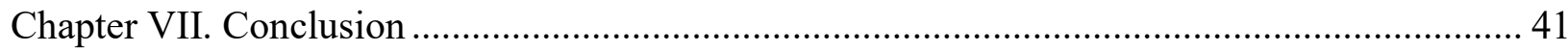

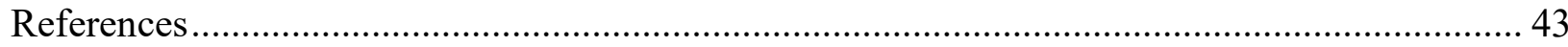

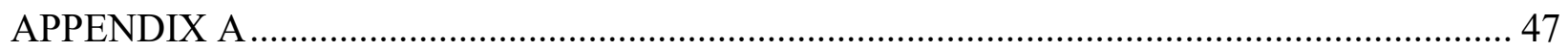

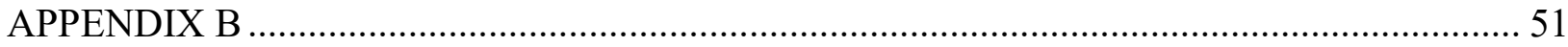

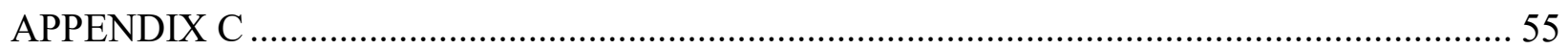

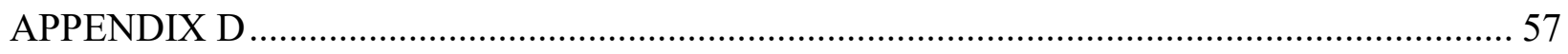


APPENDIX E 


\section{Chapter I: Introduction}

\section{Background}

Vision loss affects roughly 285 million people globally and is one of the leading causes of age-related disability which can lead to reduced quality of life (QoL) and increased levels of depression and anxiety (van der Aa, Bruin, van Rens, Twisk, \& van Nispen, 2015). In 2011, the Centers for Disease Control and Prevention (CDC) indicated vision loss to be among the top 10 disabilities for adults. Occupational therapists have been involved in the rehabilitation of individuals with low vision since the early days of the profession in 1917 (Warren, 1995). Warren (1995) discussed the emerging role of occupational therapy working with older adults with visual impairments and emphasized the importance of creating a unique and lasting contribution in this area of practice. Occupational therapy is a profession that enables individuals to participate in meaningful and purposeful activities (occupations) by helping them identify successful methods for achieving performance in their daily occupations and valued life roles (Ellexson, 2004). Occupational therapists are significant to the low vision community due to their knowledge and expertise in addressing occupational limitations while taking into consideration psychosocial factors that result from vision loss.

In the occupational therapy practice framework, activities of daily living (ADLs) are defined as "activities oriented toward taking care of one's own body which are fundamental to living in a social world and enable basic survival and well-being" (AOTA, 2014, p. S19). The practice of aesthetic techniques such as makeup application, skin care and hair styling fall under the category of personal hygiene and grooming, which is an essential basic ADL (AOTA, 2014, p. S19). In healthcare settings, the use of aesthetics is predominantly seen in senior living facilities such as skilled nursing homes, assisted living, and even hospices through in-house 
beauty salons or beauticians. In a recent UK newspaper article, Sarah Rigden, founder of Back to Beauty, provides treatments to women and men with life-limiting illnesses at North Devon Hospice in the UK. Rigden states, "It's rewarding, humbling, a privilege...they come in a little bit stressed and a little bit anxious and they go out with a smile on their face" (The Guardian, 2018). Using aesthetic techniques for personal appearance management is not only important to create a sense of individuality, but rather designed to help individuals feel better in addition to looking better.

\section{Statement of the Problem}

The literature is clear on the importance of occupational therapy for those with vision loss and how occupational therapy practitioners can help clients achieve performance in ADLs. However, there appears to be gaps in the literature related to helping the vision loss population with self-image, appearance, and performance in aesthetic techniques. Additionally, some of the literature contextualizes appearance and aesthetic enhancements in a negative light expressing that visual appearance is an oppressive mechanism that obligates women to alter their bodies in an attempt to achieve harsh beauty ideals and retain social visibility (Hammer, 2012; Clark, 2018). On the contrary, other research suggests that, "Women employ cosmetics to manipulate their appearance and in doing so, may also benefit from a boost in positive self-perception and well-being that appears to be associated with wearing makeup" (Nash et al., 2006). The literature both support and negate the importance of aesthetic enhancements, however less research has been done specifically on the effectiveness of aesthetic techniques for individuals with vision loss. Likewise, traditional occupational therapy treatment for low vision rarely address the use of aesthetics to improve an individual's self-esteem and QoL.

\section{Purpose Statement}


Currently, there are various innovative tools, assistive technology, and community organizations designed to support the lives of individuals with vision loss. One of these highly recognized organizations is the Braille Institute. The Braille Institute, with several locations throughout Southern California, is a non-profit organization which offers a wide range of free accessible programs, classes, and services to help those with blindness and vision loss achieve independence and improved lifestyles.

This capstone project will focus on the assessment of need and development of a class at the Braille Institute San Diego that highlights aesthetic techniques for individuals with blindness and vision loss, considering all genders and age groups. The purpose of this class is to help this population enhance their performance in aesthetic occupations and/or explore areas in aesthetics they may be interested in to incorporate in their daily routines. From an occupational therapy standpoint, this researcher will consider each individual's specific barriers and give advice on how to alter one's environment to produce optimal performance in self-aesthetic techniques and make recommendations to best suit each need. Lastly, this researcher intends to use knowledge and experience from occupational therapy and as a freelance makeup artist to help this population in her areas of passion.

\section{Rationale for Proposed Project}

As occupational therapists, the occupational therapy practice framework discusses the importance of using a variety of factors that empower and create possibilities to promote a client's engagement and participation in positive health-promoting occupations (Wilcock \& Townsend, 2014). Smith \& Hudson (2012) suggested that the Person-Environment-OccupationPerformance (PEOP) model "considers the interaction of intrinsic person skills, facilitators, and barriers provided by the environment, and the occupations and ability of the person necessary for 
optimal performance and participation in health" (p. 3). This model emphasizes that a person's intrinsic factors (i.e. psychological, emotional, cognitive, spiritual, and physiological aspects) and environmental (extrinsic) factors (i.e. social supports, societal stigmas and attitudes, natural and built environments, and cultural norms) either support or restrict the performance of the activities, tasks, and roles of the individual (Smith \& Hudson, 2012). To effectively implement this aesthetic program, a client-centered approach that takes into account each person's intrinsic factors, extrinsic factors, aesthetic interests, and skills must be acknowledged. Furthermore, a considerable factor to include in this program is providing each individual with the "just right" challenge. In clinical practice, occupational therapists use the "just right" challenge to enable occupational performance through enjoyable, structured, and purposeful activity that uses a combination of balance between the challenge of the task and the skill of the performer (Rebeiro \& Polgar, 1999; Csikszentmihalyi, 1990).

In occupational science, the theme of identity has been used to signify an understanding that occupation is central to the creation and expression of one's identity (Goodman, Knotts, \& Jackson, 2007). These authors also imply that when "individuals pursue goals and engage in everyday life, they experience nuanced changes in the development of their identity" (p. 102). Additionally, occupations are fundamental not just to being a person, but to being a particular person, thus creating and maintaining an identity (Christiansen, 1999). This project aims to use aesthetics in a way to help those with vision loss embrace their identity, or identities, as well as utilizing different aesthetic techniques as a form of outward expression of their own individual personalities.

\section{Significance of the Proposed Project}


A study which examined unadjusted health-related QoL among individuals with visual impairment ages 40 to 64 years found that "the percentage of individuals reporting life dissatisfaction, physical and mental unhealthy days, and days of limited activity increased as the self-reported severity of vision impairment increased" (Crews et al., 2016). Those with vision impairment are at a higher risk for depression, anxiety, and other psychological problems compared to people with normal vision (Kempen et al., 2012). The development of this aesthetics program for those with vision loss is driven by these findings. In occupational therapy, our framework lists several approaches to intervention that directs the process of service delivery and implementation of services on the basis of desired client outcomes. Using the create, maintain, establish/restore, and modify approaches from the AOTA Occupational Therapy Practice Framework (2014), this project will: 1) provide enriched contextual and activity experiences to enhance performance for people in the natural contexts of life, 2) change client variables to establish skills and/or restore skills that have been impaired, 3) provide the supports that will allow those with vision loss preserve performance capabilities they have regained to meet their occupational needs, and 4) identify ways to change the contexts or activity demands to support performance in the natural setting by using compensatory techniques (p. S33).

\section{Preliminary Project Objectives}

i. To determine what factors impact a person with visual impairments' participation in aesthetic techniques.

ii. To determine a person with visual impairments' overall perspective of their self-image.

iii. To assess an individual's comfort level in performing aesthetic occupations.

iv. To develop an aesthetic technique program for people with visual impairments. 
v. Analyze and evaluate potential results (determined by pre and post analysis) of an aesthetic program on a person with visual impairments' self-image, performance of daily activities, and QoL.

\section{Definition of Terms}

For this capstone project, aesthetic techniques are defined as the process of makeup application, skin care, and hairstyling. Context is defined as the "variety of interrelated conditions that are within and surrounding the client" (AOTA, 2014, p. S28). Environment refers to "the external physical and social conditions that surround the client and in which the client's daily life occupations occur" (AOTA, 2014, p. S28).

As stated earlier, occupational therapy approaches to intervention are "specific strategies selected to direct the process of evaluation and intervention planning, selection, and implementation on the basis of the client's desired outcomes, evaluation data, and evidence" (AOTA, 2014, p. S33). Approaches mentioned in the occupational therapy framework include create/promote, establish/restore, maintain, modify, and prevent. For this capstone project, the researcher intends to use the create, establish/restore, maintain, and modify approaches. Create refers to "an intervention approach that does not assume a disability is present or would interfere with performance and is designed to provide activity experiences that will enhance performance" (AOTA, 2014, p. S33; Dunn, McClain, Brown, \& Youngstrom, 1998, p. 534). Establish or restore is "an intervention approach designed to change client variables to establish a skill or ability that has not yet developed or to restore a skill or ability that has been impaired" (Dunn et al., 1998, p. 533). Maintain is "an intervention approach designed to change client variables to establish a skill or ability that has not yet developed or to restore a skill or ability that has been impaired" (Dunn et al., 1998, p. 533). Lastly, modify is "an approach directed at finding ways to 
revise the current context or activity demands to support performance in the natural setting, including compensatory techniques” (Dunn et al., 1998, p. 533).

Activities of daily living (ADLs) are activities oriented toward taking care of one's body whereas instrumental activities of daily living (IADLs) are defined as "activities to support daily life within the home and community that often require more complex interactions than those used in ADLs" (AOTA, 2014, p. s19). IADLs include: caring of others, caring of pets, caring of children, driving and community mobility, financial management, health maintenance, home management, meal preparation, religious and spiritual activities, safety and emergency maintenance, and shopping. The World Federation of Occupational Therapists (WFOT) identifies occupations as the everyday activities that people do as individuals, with families, and with communities to occupy time and bring meaning and purpose to life (2012). Quality of Life will be used in this project as a "multidimensional concept that is associated with a general feeling of well-being or satisfaction in the person" (Schipper, Clinch, \& Powell, 1990).

Visual impairment is a term that "encompasses both those who are blind and those with low vision (Corn \& Lusk, 2010, p. 13). The National Eye Institute (2012) defines low vision as any limitation in vision that is not correctable by medical intervention. According to the CDC (2015), common low vision conditions include:

i. Age-related macular degeneration: an eye disorder resulting in damaging central vision which is required for activities such as driving or reading

ii. Cataract: a clouding of the eye's lens due to a variety of causes and can occur at any age, including being present at birth.

iii. Diabetic retinopathy: a common complication of diabetes which is characterized by blurred or darkened vision. 
iv. Glaucoma: a condition that occurs when normal fluid pressure inside the eye slowly increases causing a gradual loss in one's peripheral vision.

\section{Assumptions}

This project makes the assumption that people with visual impairments may have low self-esteem and negative self-image, thus exhibiting a reduced QoL. Another assumption is that those with visual impairments may feel hesitant or avoid performing aesthetic techniques overall due to the nature of their visual barriers. Moreover, it is assumed that families or caregivers may be the ones performing these activities for these individuals, which diminishes the individual's ability to fully express themselves through aesthetics. Lastly, it can be assumed that these individuals may have been given recommendations on how to perform self-aesthetic techniques at some point in their lives, but carrying over learned skills may have been a challenge.

\section{Limitations}

A large limitation in this project will be the participant's voluntary involvement once selected, which may result in only seeing a participant once throughout the entire program limiting any kind of additional follow-up. With this limitation, it produces inconsistent data to demonstrate whether or not the participant absorbed any skills learned in the program. As a result, this limitation may lead to complications when formulating any outcomes and observing whether the program was effective. Another limitation is the duration when the class will take place due to the Braille Institute's trimester-basis schedule. The program will occur during the Summer 2019 trimester giving the researcher only several weeks to implement the program and collect sufficient data. Finally, the participants will only be gathered from one Braille Institute location, which is a narrow sample size, which limit the generalizability to the entire visually impaired population. 


\section{Delimitations}

There are a few delimitations to this project. First, due to the wide array of visual populations the Braille Institute serves (i.e. low vision disorders [such as macular degeneration, glaucoma, cataracts, diabetic retinopathy] or complete blindness), the program will require a variety of recommendations and specific programming to fit each individual's needs. This may affect how the structure of the class will be held, whether individual sessions or group sessions will be a better fit. Second, the site previously ran a class on fashion which briefly incorporated the topic of makeup, however the researcher was not able to observe this class ahead of time to measure any outcomes or interview any students on the effectiveness of the class. Finally, the researcher intends to train the site's staff members how to implement this program for the sake of its continuation. However, feedback from the students will determine whether they would like to continue this program for future semesters.

\section{Chapter II: Literature Review}

To further understand the purpose of this study, several significant themes must be examined in order to justify the need for this program. The researcher will analyze: 1) occupational therapy's current approaches and interventions for the visually impaired population, 2) the role of aesthetics in overall health and well-being, and 3) psychosocial factors that exist for people with visual impairments.

\section{Occupational Therapy Approaches and Interventions}

The American Occupational Therapy Association identified low vision as an emerging practice area for occupational therapy (AOTA, 2014). For people with vision loss, performing daily tasks, participating in leisure activities, and engaging in leisure activities becomes very 
challenging (Liu, Brost, Horton, Kenyon, \& Mears, 2013; Berger, McAteer, Schreier, \& Kaldenberg, 2013). In the current literature, several studies examined the effectiveness of occupational therapy interventions for vision loss using the maintain and restore approaches. In 2013, findings from a systematic review indicated that multiple components and multiple training sessions addressing ADL and IADLs are the key to low vision intervention for older adults (Liu, Brost, Horton, Kenyon, \& Mears). These interventions include education on low vision devices, training in relaxation skills, problem-solving strategies, and exchange of low vision information and resources (Liu et al., 2013). Studies from this review suggested that the use of multicomponent group interventions and multiple training sessions are effective because "older adults learned new knowledge or skills each week, for 5-8 weeks, allowing participants to apply learned knowledge and skills in their living environment even though the intervention did not occur directly at home" (Liu et al., 2013, p. 283). Another systematic review which used the same approaches examined evidence regarding the effectiveness of interventions in leisure and social participation for older adults with low vision. Findings from this review implied that the best practice guidelines to facilitate leisure and social participation include "using a problemsolving approach in either group or individual format, providing a combination of services (i.e. skills training, social support, sighted guide training, home visits), and improving task-specific lighting” (Berger et al., 2013, p. 307-308).

\section{Psychosocial Factors Associated with Vision Loss}

Vision loss is associated with psychosocial consequences which includes decreased morale, depression, social isolation, reduced feelings of self-esteem, and lower levels of social interaction (Branch, Horowitz, \& Carr, 1989). A cross-sectional study completed in Britain investigated the association between visual impairment, depression, and anxiety in older adults. 
The study found that visually impaired people had a higher prevalence of depression compared with people who had good vision (Evans, Fletcher, \& Wormald, 2007). Of these people assessed, $13.5 \%$ reported depression compared to $4.6 \%$ of people with good vision and $9.3 \%$ of people with visual impairments had two or more symptoms of anxiety compared with $7.4 \%$ of people with good vision (Evans et al., 2007).

\section{Role of Aesthetics}

The literature informs us that cosmetic interventions in healthcare settings have shown improvements in the quality of life and psychological health status of patients with psychiatric disorders and dementia (Kendrick, 2008; Hama et al., 1990; Hibino et al., 2002; Hara, 2004). In 2016, a Japanese study examined the effectiveness of a cosmetic intervention program intended to improve the psychological and social health of institutionalized older women. The program showed an improvement in the participants' level of depression measured by the Geriatric Depression Scale and an increase in the desire to participate in social activities (Hayakawa, Shoji, Kumon, Tokita, Kamata, \& Arao, 2016). Another article looked into the influence of a “Look good, feel better” program to restore the appearance-related side effects of cancer treatment for women with cancer. Testimonials from the article reiterate that the program has made women feel like themselves again and enabled them to go out in public (Kendrick, 2008). One of the women explained, "When I looked in the mirror, I didn't see a healthy face, I saw someone who was sick. Make-up makes you feel real again, makes you feel you're going back to the person you were before" (Kendrick, 2008, p. 264).

In summary, vision loss can impact one's psychosocial health and occupational therapy approaches are essential to improving quality of life of people with visual impairments. It is understood through the literature that programs that include cosmetic interventions can improve 
one's psychosocial health. However, there is a lack of literature support on the effects of using aesthetic techniques as a therapeutic intervention to increase quality of life for this specific population. Also, very few studies included male participants in their sample size. Therefore, the aim of this study is to develop a gender and age-inclusive program that uses aesthetic techniques intended to enhance quality of life and self-esteem of those with visual impairments.

\section{Chapter III: Proposed Methods and Timeline}

\section{Proposed Project Description and Participants}

The purpose of this project is to assess the need and development of an aesthetic technique program for people with visual impairments. This program will be held at the Braille Institute San Diego which serves a wide spectrum of people with varying visual impairments. The researcher will use the PEOP model in conjunction with several occupational therapy approaches to facilitate a client-centered program that addresses each individual's aesthetic needs.

For additional preparation prior to the start of the program, the researcher will attend an "Understanding Vision Loss" seminar in late March to learn about the basics of visual impairments and other skills related to assisting people who are blind and visually impaired. Not only will this seminar will provide an increased knowledge regarding the population, but it will provide an understanding of the emotional impact of sight loss as it relates to one's occupational performance.

This program will be implemented in Summer 2019. The purpose of this program will be introduced verbally by the researcher during an informal introductory session during the Spring trimester to reach students who are currently taking classes at the facility. Additionally, the 
program will be listed under the Summer trimester class schedule on the Braille Institute website. The program will be held Mondays through Thursdays for the entire trimester. Half of the participants will be allocated to the Monday-Tuesday classes and the other half will be allocated the Wednesday-Thursday class. The maximum number of participants eligible to participate is contingent upon the amount of staff members willing to assist the researcher in the program. If staff members are willing to assist with recruitment to the program, training may take approximately one week prior to beginning the program. However, if there is no staff assistance with recruiting to the program, the maximum number of participants will be limited to 10 subjects per class (e.g. 10 participants total for the Monday-Tuesday classes, 10 participants total for the Wednesday-Thursday classes), which total to 20 subjects $(n=20)$. Due to time constraints and the demands of the program, the sample size will be limited to allow adequate time to provide individual advice, make specific recommendations, and stay within a client-centered approach throughout the course of the program. The subjects will be recruited via convenience sampling during the introductory session via a sign-up sheet and through the class sign-up process. There is no age or gender requirement in order to participate. However, participants must be a registered student the Braille Institute and must have a vision impairment. Recruitment of participants who meet the inclusion criteria will continue until the maximum number of subjects $(n=20)$ have been reached. All selected subjects will need to complete an informed consent statement after a verbal account is provided to them regarding the aims and the methods of the project. Each subject will then be allocated to either the Monday-Tuesday class or the Wednesday-Thursday class, depending on their preference. This project was approved by the Institutional Review Board of the University of St. Augustine for Health Sciences. 
To maintain a hygienic environment, each subject will need their own set of supplies (i.e. makeup/skin care products, makeup application tools, and lighting equipment). Each subject will collaborate with the researcher to create a supply list prior to the start of the program, depending on what types of aesthetic techniques the subject wants to incorporate in their individualized program. Additionally, the researcher intends on coordinating field trips to the mall or department store with two or more subjects at a time to obtain the necessary supplies. The purpose of these field trips is to encourage subjects to be familiar with the occupation of shopping for their necessary supplies all while asking appropriate questions to store employees for assistance if needed. These field trips will require approval and presence of other staff members at the Braille Institute. However, if any subjects are unable to obtain necessary supplies due to financial obligations, the researcher will then require a budget from the University of St. Augustine for circumstances like these.

After each subject has obtained their necessary supplies, the researcher will cover one aesthetic topic at a time (i.e. makeup application, hair styling, skin care management, etc.) each week allowing adequate time to answer each subject's questions, address their needs, identify their barriers, and modify either the task, the environment, or the context in which they perform their aesthetic techniques. If the program receives enough positive feedback, the researcher intends to train staff members to continue the program in later semesters. Training the staff members will require duplication of the pre and post interview questions (see Appendix A \& B) either in paper or electronic format as well as a list of potential supplies and their costs (see Appendix C).

The Braille Institute San Diego's summer class schedule will begin in May 2019 and will conclude August 2019. The researcher will take four weeks prior to the start of the trimester for 
program preparation and an additional three to four weeks following the program for follow-up interviews, data analysis, and staff training for future trimesters (see Table 1 for the full timeline).

Table 1. Proposed Timeline

\begin{tabular}{|c|c|}
\hline Weeks & Tasks \\
\hline Weeks 1-2 (March 25 - April 5) & 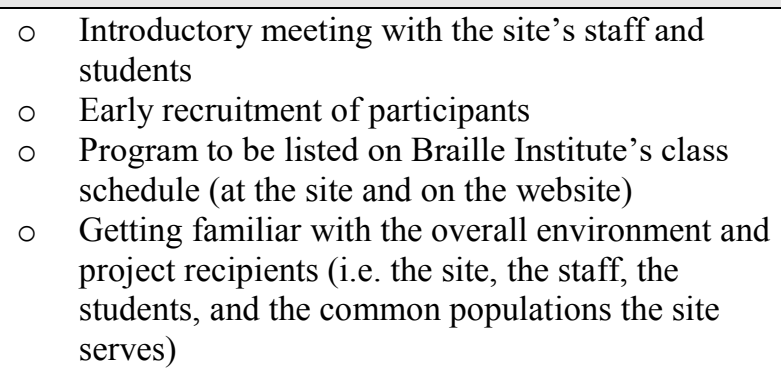 \\
\hline Weeks 3-4 (April 8 - April 19) & $\begin{array}{ll} & \text { Selection of participants } \\
\circ & \text { Training of staff members and long-term } \\
& \text { volunteers willing to help out with the program }\end{array}$ \\
\hline Weeks 5-6 (April 22- May 3) & $\begin{array}{ll}\circ & \text { One-on-one interviews }\end{array}$ \\
\hline Weeks $7-14$ (May 6-June 28) & $\begin{array}{ll} & \text { Shopping for supplies } \\
\circ & \text { Aesthetic technique program (one aesthetic topic } \\
\text { to be covered per week) }\end{array}$ \\
\hline Weeks $15-16$ (July $1-$ July 12 ) & $\begin{array}{ll} & \text { Follow up interviews, analyzing data from } \\
\text { interviews, observations } \\
\circ & \text { Staff training for continuation of program in future } \\
\text { trimesters }\end{array}$ \\
\hline
\end{tabular}

Note. Exact timeline may be subject to change throughout the capstone experience.

\section{Proposed Study Design}

This project will utilize a mixed-methods design using a pre and post oral interview to measure the effectiveness of the aesthetic technique program. Prior to the start of the program, each subject will participate in an oral interview (see Appendix A) that consists of nineteen items with a combination of open-ended and Likert-type, closed-ended questions. This interview examines each subject's specific visual impairment(s), aesthetic abilities, aesthetic interests, selfimage perception, and what they intend to learn in the program. The researcher will conduct individual face-to-face oral interviews that will be audio recorded for data analysis purposes. This interview will take place at the site itself and will take approximately 45 minutes to 
complete. This method of data collection was chosen to elicit appropriate responses to questions that may be of sensitive nature, but most importantly, to establish rapport with each subject.

\section{Proposed Analysis}

Qualitative data extracted from the initial interview will be transcribed, analyzed, and coded. Quantitative data will be statistically analyzed from the Likert-type questions. Following the program, a two-week follow-up interview (see Appendix B) will then be administered in this same format to measure the program's effectiveness and include any additional feedback and/or recommendations for further improvements of the program. Data that compares findings from the initial interview and the follow-up interview will then be reported. The themes that emerge from qualitative data will be reported in descriptive format and significance from quantitative data will be reported in numerical percentages in a table format. Both the qualitative themes and numerical data gathered from the interviews will provide support for the implications of aesthetic techniques as part of an occupational therapy intervention for individuals with vision impairments.

\section{Envisioned Next Steps}

Following the program, the researcher will use data extracted from the interviews to create implications for occupational therapy practice. Furthermore, if the program turns out to be effective, the recommended ideas and feedback from the participants will be used for improvements to continue the program in future trimesters at Braille Institute to better serve the population. Lastly, future research and planning would be beneficial in using the significance of this program to serve other populations (such as the aging community, people who have terminal illnesses, people with dementia and/or Alzheimer's, etc.). 


\section{Chapter IV: Actual Methods and Timeline}

During the initial weeks of the capstone experience, Braille Institute San Diego revealed they will be undergoing changes that will affect the duration and timing of their classes moving forward. This affected the researcher's initial proposed timeline. Instead of their regular 16-week trimesters, they now have three 5-week continuous sessions per trimester. Due to this unforeseen change, the aesthetic techniques program had to be postponed in its schedule and was held during the second 5-week session of the trimester from June $10^{\text {th }}$ to July $11^{\text {th }}$. The contents and topics of the program can be seen on Table 2 .

Although timing issues arose during the capstone experience, the timing of a new addition to the Braille Institute team was an appropriate fit. Just a month prior to the start of the capstone experience, the first occupational therapist at Braille Institute San Diego was hired as the low vision specialist. With this exciting addition to the team, Braille Institute will also move forward hiring only certified occupational therapy assistants (COTA) as their independent living skills instructors. The COTA instructors will be under the supervision of the low vision occupational therapist. This change toward an occupational therapy based approach will create future classes to be more client-centered and goal-focused, thus endorsing a progressive learning environment. Additionally, this addition of OT allows the aesthetic techniques class to be continued by a COTA instructor in future trimesters.

To fully maximize the capstone experience, the researcher spent two weeks shadowing the low vision occupational therapist. During this time, the researcher gained insight regarding the various roles and responsibilities of a low vision occupational therapist in this setting. The researcher was able to: (1) gain knowledge regarding the different spectrum of eye diseases, (2) observe evaluations to learn how a low vision occupational therapist can help a person maximize 
their remaining vision, (3) learn about the client intake process and ophthalmology referral form, and (4) learn about the OT and COTA relationship. Additionally, the low vision occupational therapist provided useful recommendations for the researcher's aesthetic technique program. Overall, the low vision occupational therapist became an exceptionally valuable resource throughout the entire duration of the capstone experience.

Lastly, the researcher reached out to nearby retail stores to request their involvement for the students' shopping trip experience as part of the aesthetic techniques program. Of the eight stores that were contacted, five of the stores - L'Occitane ${ }^{\circledR}, \operatorname{Lush} \AA$, Sephora ${ }^{\circledR}$, The Body Shop ${ }^{\circledR}$, and Kiehl's ${ }^{\circledR}$ - agreed to take part in the shopping experience. L'Occitane ${ }^{\circledR}$ also happens to incorporate braille on their packaging. The overall purpose of the shopping trip was to increase a student's comfort level in the occupation of shopping. The students were given this opportunity to interact with the store employees to gain product recommendations that would be suitable for them. Additionally, they were encouraged to try on the actual products. All students left with product samples and a few of them were able to purchase products.

Both the students and the store employees fully benefited from the experience. All store employees stated they have never worked with customers who have a vision impairment in the past. However, this experience taught them how to support customers with vision impairments in the future, truly appreciating this unique opportunity. Furthermore, two of the stores, L'Occitane ${ }^{\circledR}$ and The Body Shop ${ }^{\circledR}$, generously donated bags of full-sized products to the students and reached out to the Braille Institute San Diego offering support for future aestheticrelated programs. 
Table 2. Actual Timeline

\begin{tabular}{|c|c|c|}
\hline Weeks & \multicolumn{2}{|c|}{ Tasks } \\
\hline Weeks $1-2($ March 25-April 5) & $\begin{array}{l}0 \\
0\end{array}$ & $\begin{array}{l}\text { Introductory formal meeting with the site's staff } \\
\text { Become familiar with the overall environment and } \\
\text { project recipients (i.e. the site, the staff, the } \\
\text { students, and the common populations the site } \\
\text { serves) } \\
\text { Observe current classes }\end{array}$ \\
\hline Weeks $3-5$ (April 8-April 26) & ○ & $\begin{array}{l}\text { Market aesthetics technique classes to students } \\
\text { (formal \& informal) } \\
\text { Observe low vision occupational therapist roles } \\
\text { and duties } \\
\text { Submission of Institutional Review Board (IRB) } \\
\text { Application for research study }(4 / 10 / 19) \\
\text { Study approval from IRB }(4 / 16 / 19)\end{array}$ \\
\hline \multicolumn{3}{|l|}{ **Mandated University Spring Break } \\
\hline Weeks 6-9 (May 13-June 7) & $\begin{array}{l}0 \\
0\end{array}$ & $\begin{array}{l}\text { Continue marketing aesthetic techniques classes } \\
\text { Contact nearby retail stores to be involved in } \\
\text { shopping trip experience } \\
\text { Recruit students } \\
\text { Create lesson plan for aesthetic techniques classes }\end{array}$ \\
\hline Weeks $10-14$ (June 10-July 12) & & $\begin{array}{cl}\begin{array}{c}\text { Aesthetic techniques classes (5-week session) } \\
\text { ("Skincare \& Hairstyling 101" every }\end{array} & \begin{array}{l}\text { Monday/Wednesday, "Makeup 101" } \\
\text { every Tuesday/Thursday) }\end{array} \\
\text { Week } 1 & \\
\circ & \text { Introduction/Ice breaker } \\
\circ & \text { Introduce importance of class } \\
\circ & \text { Go over basic skincare and makeup } \\
& \text { products } \\
\circ & \text { Conduct pre interviews } \\
\text { Week } 2 & \\
\circ & \text { Shopping trip experience } \\
\circ & \text { Conduct pre interviews } \\
\circ & \text { One-on-one appointments } \\
\text { Week } 3 & \\
\circ & \text { Create homemade sugar scrubs } \\
\circ & \text { Create basic makeup kit } \\
\circ & \text { Create basic skincare kit } \\
\circ & \text { One-on-one appointments } \\
\text { Week } 4 & \\
\circ & \text { Go over hair care, heatless hairstyling } \\
\circ & \text { Create apple cider vinegar spray for hair } \\
\circ & \text { Practice makeup techniques } \\
\circ & \text { One-on-one appointments } \\
\text { Week } 5 & \\
\circ & \text { Go over healthy diets/healthy tips to } \\
& \text { maintain good skin and hair } \\
\circ & \text { Closing discussion } \\
\circ & \text { Share resources with one another } \\
& \text { Photoshoot }\end{array}$ \\
\hline
\end{tabular}




\begin{tabular}{|l|ll|}
\hline Weeks 15-16 (July 15 - July 26) & $\circ$ & Conduct post interviews \\
& $\circ$ & Create binder of all notes and resources used in the \\
& aesthetic techniques class to leave for Braille \\
& Institute \\
& $\circ$ & Data analysis \\
\hline Weeks 17-19 (July 29-Aug 16) & $\circ$ & Completion of capstone paper rough draft \\
& $\circ$ & Completion of capstone project poster presentation \\
\hline & $\circ$ & Revision of capstone paper \\
& $\circ$ & Revision of capstone project poster presentation \\
& $\circ$ & Submission of capstone paper final draft \\
& $\circ$ & Submission of capstone project poster presentation \\
& $\circ$ & Capstone project presentation at Braille Institute \\
& $\circ$ & Capstone project presentation at University of St. \\
& \\
\hline
\end{tabular}

\section{Participants}

The subjects were recruited via convenience sampling by signing-up with the Braille Institute student advisor during the lunch hour within the weeks leading up to the session. A few subjects also called the student advisor to sign up for the classes. The single inclusion criteria is that subjects must be a registered student at the Braille Institute San Diego. The requirements to be a registered student at the Braille Institute San Diego are to be 18 years old or above and must have a vision impairment. Beyond that, there are no further age or gender requirements in order to participate.

In order for the program to appeal to both female and male students, two separate classes were formed. These classes were titled "Skincare and Hairstyling 101" (the more gender-neutral class) and "Makeup 101". "Skincare and Hairstyling 101" was offered Mondays and Wednesdays at 11:00 AM and "Makeup 101" was offered on Tuesdays and Thursdays at 11:00 AM. In addition, the researcher offered separate one-on-one appointments during afternoon office hours for students who wanted extra time to practice their techniques.

The classes were introduced to the students weeks ahead of the start of the session. The classes were added to the Braille Institute class catalog which could be accessed in-person and online. Additionally, the researcher marketed the class formally by speaking during the lunch 
hour special announcements and informally through casual conversations with the students. The researcher then introduced the class to the staff and administrators at a formal weekly staff meeting. The staff and administrators gave a very welcoming response. They even advertised the class to the students they feel would benefit from it the most. The researcher was also invited to observe various classes to gain a better understanding of how to implement the aesthetics techniques classes.

A total of twenty-two subjects were enrolled in the classes. Thirteen students were enrolled in "Skincare and Hairstyling 101" and eleven students were enrolled in "Makeup 101". Two students were enrolled in both classes and seven students sought additional one-on-one help with the researcher during office hours. The class was a 50-minute session per day from 11:00AM - 11:50AM. This went on for four days a week for five consecutive weeks. The oneon-one sessions were one to two hours long, depending on the student's preference. The researcher encompassed occupational therapy approaches (create, establish/restore, maintain, and modify) during the aesthetic techniques classes to ensure that each student's needs were addressed. This project was approved by the Institutional Review Board of the University of St. Augustine for Health Sciences prior to initiation of the study.

\section{Study Design and Data Collection}

This project utilized a mixed-methods design using a pre and post oral interview which consists of quantitative and qualitative questions as an outcome measure for the aesthetic techniques classes (see Appendix A \& B). The pre and post interviews consisted of items with a combination of open-ended and Likert-type, closed-ended questions. These questions examine themes that pertain to self-image perception, confidence with aesthetic performance, aesthetic interests, and learned techniques. While many questions were of sensitive nature, participants 
answered all the questions. Out of the twenty-two subjects, fifteen were consistent participants of the class. Of the fifteen subjects, one had both a vision and hearing impairment, therefore had difficulty completing the interview. The remaining fourteen subjects completed the interviews in its entirety which provided the pre and post data. All pre interviews were conducted on-site at the Braille Institute. Eleven post interviews were conducted on-site and three post interviews were conducted over the phone. Each interview respondent was numerically assigned to maintain confidentiality. Each interview was audio-recorded and transcribed. Each interview took approximately 15 minutes to complete. Once transcription was complete, the audio-recorded interviews were deleted. Each interview respondent gave verbal consent to be audio-recorded.

\section{Chapter V: Data Analysis and Results}

\section{Data Analysis}

Quantitative interview results were analyzed using Microsoft Excel® to formulate visual and descriptive statistics to report frequency counts and percentages. Qualitative interview results were analyzed using content analysis to identify emerging themes. The researcher, an occupational therapy graduate student, independently analyzed data from the pre and post interviews. The researcher then compared and contrasted this data to develop overall study conclusions.

Out of twenty-two students who participated in the class, fourteen students completed the survey, yielding a $67 \%$ response rate. The majority of the respondents were female $(93 \%)$ and had varying visual impairments (see Figure $1 \& 2$ ). Of the respondents, the most common eye disease reported was retinitis pigmentosa $(36 \%)$, the second most common was a tie between age-related macular degeneration (21\%) and diabetes-related vision loss/diabetic retinopathy 
(21\%), followed by accident-related or trauma-related vision loss $(15 \%)$, and retinal detachment (7\%). All respondents were diagnosed as legally blind.

Figure 1. Cause of Vision Impairment in Class Participants

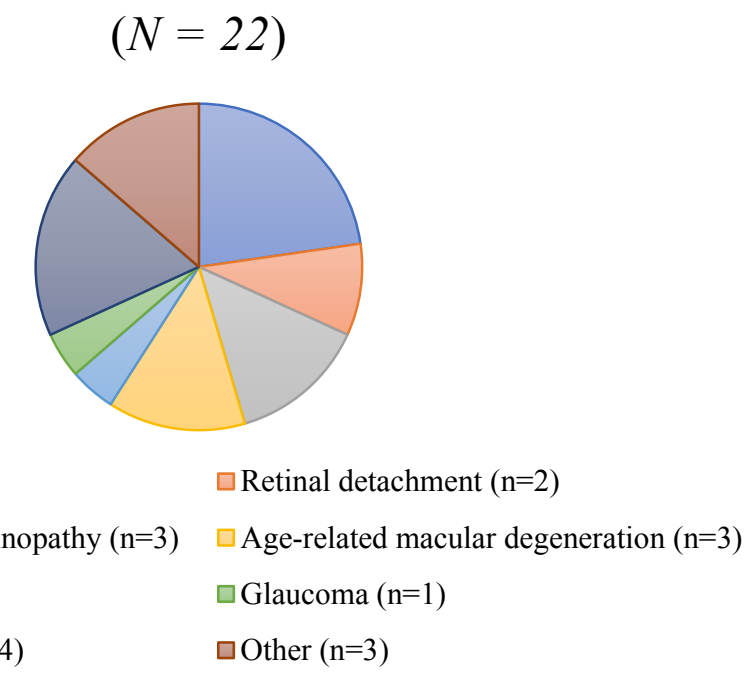

Figure 2. Cause of Vision Impairment in Interview Respondents

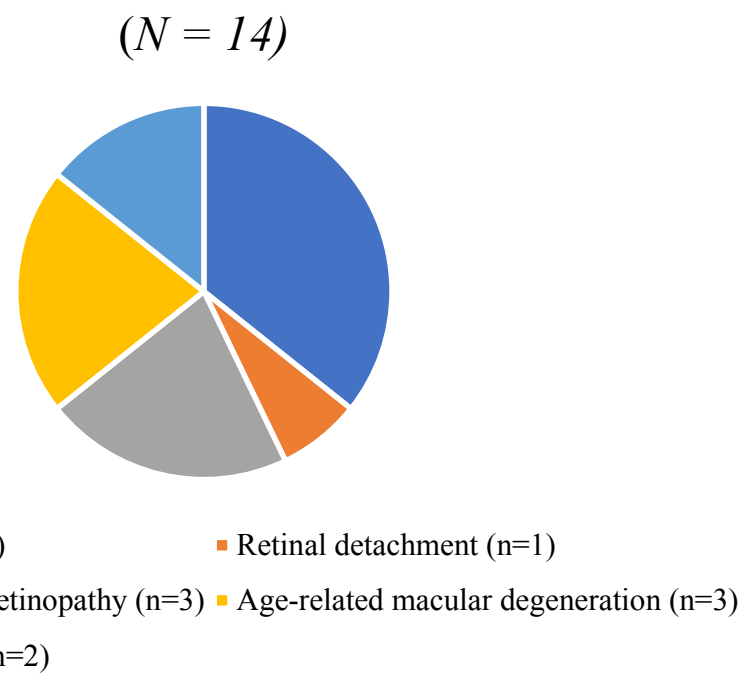

\section{Pre and Post Interviews}

Twenty-one questions were asked in the pre interview and fifteen in the post interview. Nine of the pre and post interview questions were worded the same way and quantitative in 
nature. These questions were used as quantitative outcome measures to explore the effectiveness of the aesthetic techniques program. Table 3 lists these questions and their responses. The remaining questions asked were qualitative in nature. Interview responses and observations from these qualitative questions revealed three themes that emerged from the aesthetic techniques program: (1) confidence and self-esteem, (2) addressing the needs for aesthetic techniques in a vision impaired community, and (3) advocating for personal autonomy.

\section{Quantitative Results}

The first question of the pre interview asks respondents if they were taught aesthetic techniques after acquiring their vision impairment. The majority (71\%) answered "no". The following questions were worded similarly to compare the pre and post responses. Respondents were asked if they perform aesthetic techniques on their own. All respondents (100\%) answered "yes" in both the pre interview and post interview. They were then asked to describe how confident they feel performing aesthetic techniques. $43 \%$ responded "very confident" in the pre interview which increased to $79 \%$ responding "very confident" in the post interview. In addition, $14 \%$ responded "not confident" in the pre interview which decreased to no students $(0 \%)$ responding "not confident" in the post interview. They were asked if they rely on others to help them perform aesthetic techniques. The results matched in the pre and post interviews with 14\% responding "yes" and 86\% responding "no". They were then asked if they feel comfortable shopping for aesthetic related supplies. Only $21 \%$ responded "very confident" in the pre interview and increased to $79 \%$ responding "very confident" in the post interview. They were asked how satisfied they are with their self-image. $14 \%$ responded "very confident" in the pre interview and increased to $86 \%$ responding "very confident" in the post interview. 
They were asked if their self-image makes it difficult to fulfill their roles in life. $29 \%$ responded "somewhat difficult" in the pre interview and no student $(0 \%)$ responded "somewhat difficult" or "very difficult" in the post interview. 71\% responded "not difficult" in the pre interview and all students (100\%) responded "not difficult" in the post interview. They were asked if their self-image makes it difficult to participate in work, leisure activities, and hobbies. $36 \%$ responded "somewhat difficult" or "very difficult" in the pre interview and only $7 \%$ responded "somewhat difficult" or "very difficult" in the post interview. 93\% responded "not difficult" in the post interview. Furthermore, all respondents (100\%) reported they were "very interested" in learning new aesthetic techniques when asked in the pre interview.

Table 3. Quantitative Results of Pre and Post Interview Responses

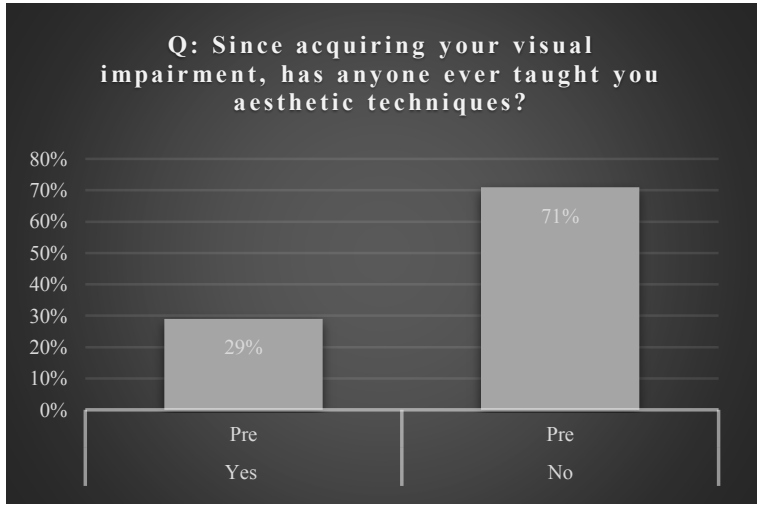

Q: Do you perform aesthetic techniques on your own?

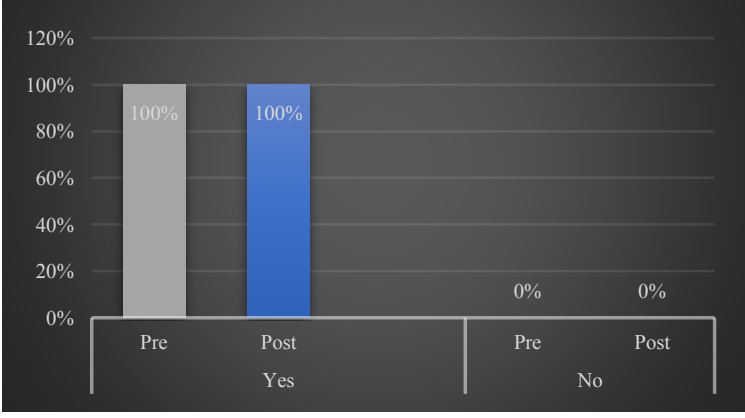

Q: How satisfied are you with your selfimage?

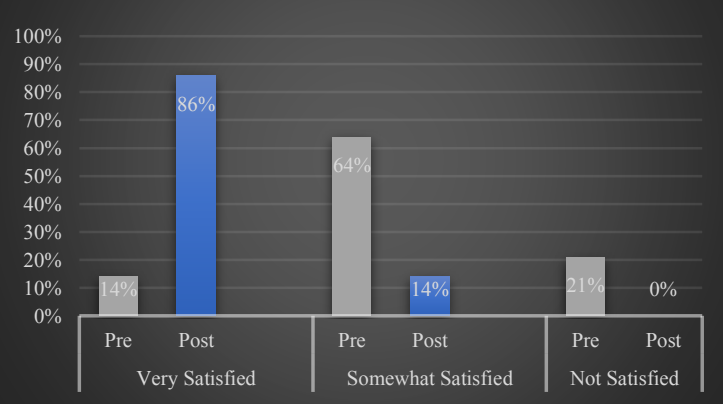

Q: Do you feel self-conscious engaging with others because of your self-image

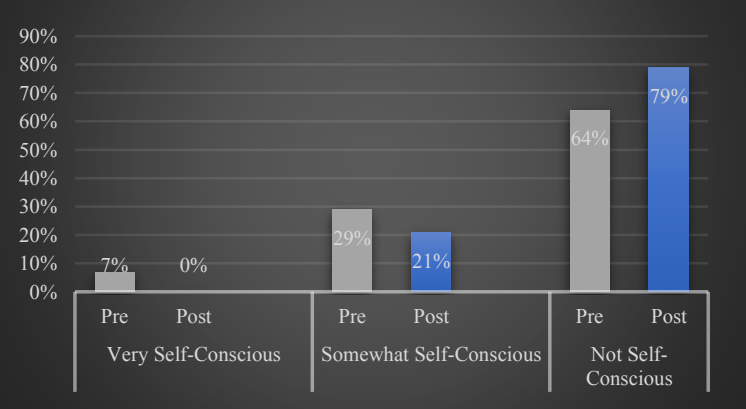



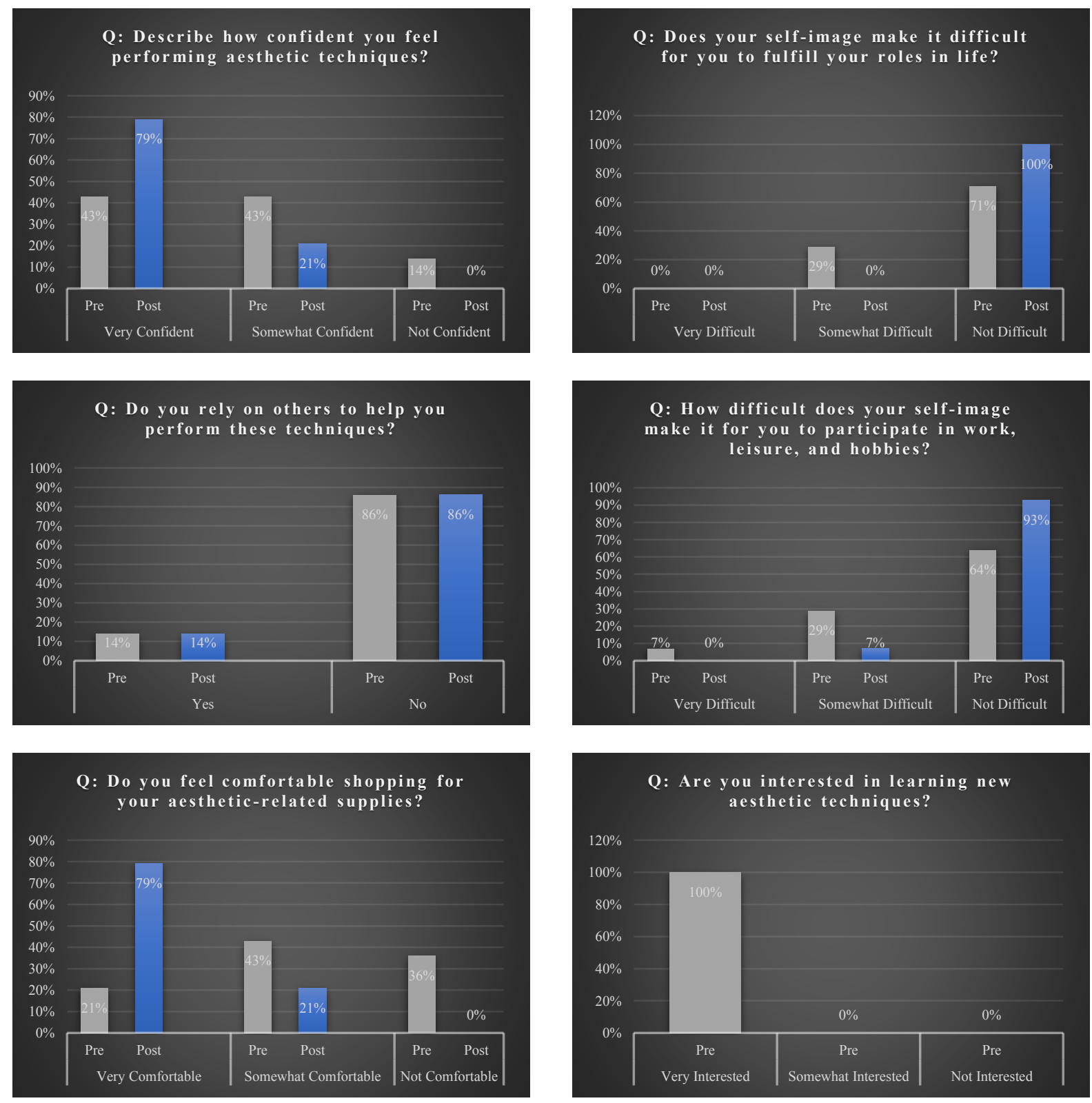

\section{Qualitative Results}

Confidence and Self-Esteem. Interview respondents reported in the pre interview that they struggle with self-worth. They had low self-confidence and struggled performing aesthetic techniques due to a variety of challenges. Common challenges mentioned are: lack of or limited ability to recognize their own facial features, difficulty identifying and differentiating between products, feeling unsure of how much product they are applying, not knowing the sequence in an 
aesthetic regimen (i.e. skin care routine, makeup routine), and feeling uncertain of which products to use. Additionally, many respondents did not feel comfortable performing the occupation of shopping. These concerns were taken into account by the researcher and were addressed in the aesthetic techniques classes. Supplemental resources (i.e. class notes, tip sheets, a list of affordable products, recipes for homemade products) were given to the students either electronically, in enlarged print, in braille, or in audio format (see Appendix D for supplemental resources). Students were then encouraged to practice their learned techniques at home to improve carryover in performance.

The post interview responses revealed that students' confidence level and self-esteem had improved. This was also confirmed through observations from the researcher and Braille Institute San Diego staff members. Respondents were asked if the class addressed challenges they faced when previously performing aesthetic techniques and what they gained from taking the class. One student responded:

"This class impacted my life. The simple techniques you taught us about re-orienting ourselves with our face to see where our facial features are or how it may have changed has really helped me. I feel more confident when I'm putting on my makeup and doing my skin care routine. This class encourages me every day to do self-care techniques because it's part of our self-image. My self-esteem has improved. . I was getting depressed and had anxiety, but when I started doing something that I know is right for me, that accomplishment makes your self-esteem grow. You have given me the feeling of empowerment that I was missing." 
Another student reported gaining confidence along with a positive shift in her self-esteem. She received compliments not only from the Braille Institute San Diego staff, but from family members and her significant other. She explained:

"My boyfriend asks why I'm looking good these days. I tell him that I just want to look extra good sometimes. It doesn't have to only be on special occasions. I want to put the effort for myself."

In summary, students collectively reported that the biggest take-away from participating in the aesthetic techniques classes was an increase in confidence and self-esteem. This was the most common theme mentioned in the post interviews. Students reported feeling more hopeful and empowered to take on new activities and challenges that they neglected in the past, regardless if it relates to aesthetic techniques.

\section{Addressing the Needs for Aesthetic Techniques in a Vision Impaired Community.}

The class included a combination of class participants who were unfamiliar with aesthetic techniques and some who currently incorporated aesthetic techniques in their daily routines. Despite their varying knowledge and skills regarding this occupation, all participants shared the same belief: self-care is an important part of life. They questioned why an aesthetic-related class has never been introduced to them before. They all expressed excitement after finding out that a class like this is finally going to happen.

One student described that she hardly explored any aesthetic techniques after losing her sight, feeling intimidated to even try. When she heard that this class was being offered, she was eager to give it a try in hopes of learning new things that can be applied in her daily life. She stated, "This class opened a door in my life that I kept closed. . . Before I wasn't doing anything. . Now I'm taking the first step. I'm taking care of myself in a better way than before." A young 
student in her twenties expressed interest in the class due to the fact that she was attending school and wants to look presentable in front of her peers. She revealed feeling behind in many aspects of her life compared to her sighted peers. She explained, "it's really important that I know how to do these techniques. I want this class to continue because it will benefit schoolgoing girls like me who want to feel like they belong with their peers."

Another student who already performed aesthetic techniques described why this class was important to her. She reported that she plans on going back to work. Therefore, learning aesthetic techniques that would make her look more professional is extremely beneficial. She further explained:

"During my first interview at Braille, the low vision specialist back then asked me, 'What is the most challenging thing to do?' I said the most challenging thing to do was putting on my makeup. Makeup for me makes me feel good, beautiful, and confident. Being someone who was previously sighted, I've always been trained to look the best for any occasion... Dress up, wear makeup, do your hair. . . But how come no one ever taught us these things? Ever since I started taking programs for the blind, nobody has ever touched on the topics discussed in this class."

Aside from this student, numerous students who already had previous knowledge in aesthetic techniques still reported feeling unsure of their methods. They questioned if they are applying the right amount of makeup or if they are blending everything correctly. The researcher listened to these struggles and aimed to improve them in the new techniques that were going to be taught. Some examples of these techniques include: (1) using the counting method to ensure products such as eyeshadow, bronzer, or blush are even on both sides of the face, (2) using fingers to first apply the product followed by a brush to blend the product, (3) using sensory 
techniques such as a cold lip brush so one can feel the coldness to where they are applying, (4) labeling skin care products with tactile markings, in braille, or numerically, (5) using tactile markings to differentiate between different colors and shades, (6) organizing products in the correct sequence in which they will be used, and (7) placing items in the same spot to know where everything is located. These techniques, along with many others, were addressed in the class.

In summary, all students reported sharing the same interest in taking a class related to aesthetics and self-care. They recognize the importance of looking presentable and aspire to continue making progress in this occupation. Lastly, they all wish for this class to continue in future semesters.

Advocating for Personal Autonomy. Respecting a person’s autonomy “acknowledges a person's right to hold views, to make choices, and to take actions based on [his or her] values and beliefs" (Beauchamp \& Childress, 2013, p. 106). Autonomy has been discussed time and time again in occupational therapy practice and code of ethics. This aesthetics class addressed the importance of preserving one's personal autonomy and the right to make decisions in the quest for independence and increased quality of life.

Several students reported that once they lost their sight, they felt they too lost their autonomy. One student reported that her family member would shop for her instead of taking her on the shopping trips or even consulting her first. Aside from shopping, she described other situations in which she felt her decisions not being taken into account. Unfortunately, this lack of consideration has happened for many years that she eventually grew comfortable with the idea. After participating in the class, she stated: 
"Not only are we learning personal care, but our families are noticing the change. For so many years, they [her family] didn't understand. Sometimes, they buy my things and I don't have a choice in what they buy. Now I know I have the choice and I can go to the store with them. The first thing I learned in this class is that I need to do something for myself. I learned many things, but that is the most important for me."

Another student described the struggles of doing nice things for herself after a family member told her she was "broken for losing her sight." During the interview, this student became emotional and it was apparent that the words her family member said to her impacted her for many years. She disclosed:

"I have been down for a long time because of what my family said to me. This class teaches us that we have the right to take care of ourselves and feel good. . . This class was a reminder that "I can do this." Just because I'm blind doesn't mean I can't do this. . You made a big difference and helped me not listen to anyone who says differently. I even started dating again after my husband passed away. I sent the gentleman a photo of me after getting all prettied up and he said I was so beautiful. It made me feel good. This class has boosted my spirits."

In summary, students were not only taught the importance of autonomy in their personal lives, but to take matters into their own hands by advocating for increased accessibility. They were taught to fully exercise their rights in order to live a life based on their own terms.

\section{Chapter VI: Discussion}

The aesthetic techniques program provided students with the skills they need to increase their self-confidence, self-esteem, and occupational performance in aesthetics. After acquiring 
their visual impairment, the majority of respondents (71\%) stated they have never been taught aesthetic techniques. However, all (100\%) respondents stated that they are "very interested" in learning new techniques. These statistics show that knowledge of aesthetic techniques is an unfulfilled need that existed in their lives. Once the class concluded, feedback from all respondents claimed great interest if this class were to continue in later terms. Fortunately, a Braille Institute San Diego volunteer has agreed to teach the class in the third session. All contents and information addressed in the current aesthetic technique program were provided to the volunteer (see Appendix D). Additionally, the researcher gave a formal presentation to the staff and administrators at Braille Institute San Diego. This presentation examined the aesthetic techniques program, the results of the interviews, and future implications of practice within this field (see Appendix E).

Throughout the entire program, staff and administrative members at Braille Institute San Diego acknowledged the physical and psychosocial change in the students who participated in the class. A counselor at the site reported that this program helped a student feel "more human" again after participating in the shopping trip and aesthetic techniques classes. A program and events manager at the site described how students were enthusiastically coming into her office to showcase their learned techniques. Even the site's receptionist noticed changes such as how students entered and exited the building with a more positive demeanor than before.

Each class session, students were even reporting the positive changes that their families, peers, romantic partners, and other members of the community were noticing. These changes encouraged a few students to take on new roles and occupations, including ones they might have neglected before. One student who also happens to be a cancer survivor explained that vision loss accompanied with the effects of chemotherapy became the reason why she neglected 
performing aesthetic techniques in the past. In her pre interview, she stated, "I felt hopeless before, but I believe this class is going to make me feel better and look better ... especially now that I started dating again. My goal is to get out more often, meet someone special." Since then, this student revealed that she went on two dates with an old acquaintance and plans on continuing the friendship in the future.

Finally, interview results indicate that this program helped students gain a sense of empowerment. This includes being an advocate for themselves and their personal autonomy. The interview triggered emotional responses from a few students who explained how their family members would sometimes fail to provide the support they need to live an independent life. A life in which they have the right for self-determination and choice. It brings up the question: if some of these individuals are seldom excluded of choice from their very own family members, what about the supports they need from society - a societal world that is mostly sighted? Aceim \& Mazzotta (2013) suggest, “A visually impaired person living an autonomous and independent life can help fight the stigma of disability and approach the social standards of normality. In order to fully exercise their autonomy, a person with vision impairments must obtain the support from society to increase accessibility in more occupations". However, it is not up to these individuals to wait for society to change. The researcher aimed to help students understand the importance of being a self-advocate to enable a life that is full and autonomous, as each individual deserves.

\section{Limitations}

This capstone project and related research posed several limitations. The researcher was unable to seek out a peer reviewer to confirm themes that emerged from the qualitative analysis. Once the aesthetic techniques program had concluded, there was limited time to follow up with 
the interview respondents to seek out respondent validation to validate the final themes and concepts that were reported. Additionally, researcher bias may have the potential to influence the data collection due to the fact that the sole researcher provided the aesthetic techniques classes and administered the student interviews.

In regard to the capstone project, the aesthetic techniques classes, "Makeup 101" and "Skincare and Hairstyling 101", were not listed on the original Summer term class catalog. The class catalog had already been printed and uploaded online before the researcher arrived at the site. The aesthetic techniques classes were later added to the class catalog, but not all students were aware of this change causing several students to miss out on the opportunity to enroll for the classes from the beginning. Moreover, the classes were added to an already structured class schedule which meant they were only allotted one time slot per day. The duration of the classes was also only five weeks long as opposed to twelve weeks long from the proposed timeline.

Furthermore, the majority of students did not understand the difference between "Makeup 101" and "Skincare and Hairstyling 101". The reason they had to be separated was to appeal to both female and male students. The classes were also offered on separate days. Thus, students who only attend the site once a week were only enrolled for whichever class was offered on that day. In turn, students taking the "Skincare and Hairstyling 101" class were not able to learn topics such as makeup application. Likewise, students taking the "Makeup 101" class were not able to learn hairstyling techniques. However, fundamental topics such as skincare overlapped into both classes. To solve some of these issues, the researcher still provided students with supplemental notes from both classes and offered any techniques to be covered during office hours. 
Finally, students had varying forms of visual impairments which meant each student had different needs. Given that they had different needs, a simple "one-size-fits-all" teaching method is impractical. For example, a student with total blindness may require additional time to grasp the foundational knowledge and purpose of products and how to use them. That student may benefit from one-on-one training to learn the activity demands and actual performance skills of techniques they are being exposed to for the first time. It is not pragmatic to learn techniques with a group of students who were previously sighted and already have existing knowledge of the activity demands and performance skills.

\section{Implications for Occupational Therapy Practice and Future Projects}

This project demonstrated that an aesthetic-related program was able to positively impact the lives of people with visual impairments. This program was able to fulfill a vital need in their community - a need that many practitioners have failed to address in the past. To optimize quality of life and performance outcomes in aesthetic-related occupations for people with visual impairments, occupational therapy practitioners should: (1) address psychosocial themes in relation to aesthetics such as self-image, self-confidence, and satisfaction with one's identity during initial evaluations, (2) consult professionals involved in the field of aesthetics and collaboratively problem-solve ways in which a person can perform their meaningful aestheticrelated occupations, (3) refer a person with low vision to a specialized low vision occupational therapist to address lighting, magnification, glare, and how to maximize one's vision to enhance performance in aesthetic techniques, and (4) encourage self-advocacy and address any specific issues regarding personal autonomy in the occupation of aesthetics.

Furthermore, occupational therapy practitioners should increase awareness to the sighted world to make an effort to design products for accessibility. Future projects should include 
advocating to product designers, developers, and government regulators to design products with accessibility in mind. During the shopping trip experience, many products were designed similarly, creating barriers for students to identify one product from another. The students would have to take the extra steps in order to modify their products to make them more identifiable. That extra time could be saved if products originally had specific designs or markings to differentiate between similar-looking products. Thankfully, L'Occitane ${ }^{\circledR}$ has made a breakthrough in accessible design and included braille descriptions on their packaging and actual product itself. Other companies, however, are behind in this regard. Increased accessibility in packaging, design, and usability of aesthetic-related products would greatly decrease challenges people with visual impairments face when performing aesthetic occupations. Examples include: labeling products with braille writing and tactile markings, enhance contrast and size of product descriptions, and at a minimum, use colors to differentiate between similarly packaged products. This can be done by product designers looking to increase their customer base and improve their product image, or by a government issued mandate requiring them to do so. Advocating for accessibility in products would enhance performance in aesthetic-related occupations and contribute to a more inclusive society for everyone.

\section{Chapter VII: Conclusion}

This capstone project sought to enhance the quality of life of people with visual impairments through aesthetic techniques. The researcher used a variety of avenues to provide support to achieve this goal: program development, education, and advocacy. The program was able to increase feelings of self-worth in participants along with feelings of empowerment to create new possibilities. Gaps in the literature and interview data from participants revealed a 
significant need in aesthetic technique training that has not been addressed in the past. Given such a high percentage of interest in this topic, it is likely that other people in this population feel a similar need that needs to be explored. The lack of studies and programs on aesthetic techniques for people with visual impairments highlight the importance of research and program development aimed at enabling this population to live a full and satisfied life. Therefore, further research, projects, and advocacy work is greatly needed. 


\section{References}

Aciem, T., \& Mazzotta, M. (2013). Personal and social autonomy of visually impaired people who were assisted by rehabilitation services. Revista Brasileira de Oftalmologia, 72(4), 261-267. https://dx.doi.org/10.1590/S0034-72802013000400011

American Occupational Therapy Association. (2014). Low vision. Retrieved from http://www.aota.org/en/ Practice/Productive-Aging/Emerging-Niche/Low-Vision. Aspx

American Occupational Therapy Association. (2014). Occupational therapy practice framework: Domain and process (3rd ed.). American Journal of Occupational Therapy, 68(Suppl. 1), S1-S48. http://dx.doi.org/10.5014/ajot.2014.682006

Barstow, B. (2018). Occupational therapy and low vision rehabilitation: Future Directions. British Journal of Occupational Therapy, 8(1), 3-4. Retrieved from http://prxusa.lirn.net/login?url=http://search.ebscohost.com/login.aspx?direct=true \&db=edo\&AN= $127118095 \&$ site $=$ eds-live

Berger, S., McAteer, J., Schreier, K., \& Kaldenberg, J. (2013). Occupational therapy interventions to improve leisure and social participation for older adults with low vision: A systematic review. American Journal of Occupational Therapy, 67, 303-311. http://dx.doi.org/10.5014/ajot.2013.005447

Baum, C. M., Christiansen, C. H., \& Bass, J. D. (2015). The Person-Environment-OccupationPerformance (PEOP) model. In C. H. Christiansen, C. M. Baum, \& J. D. Bass (Eds.), Occupational therapy: Performance, participation, and well-being (4th ed.), 4956. Thorofare, NJ: SLACK Incorporated.

Branch, L. G., Horowitz, A., \& Carr, C. (1989). The implications for everyday life of incident self-reported visual decline among people over age 65 living in the community. Gerontologist, 29(3), 359-365.

Beauchamp, T. L., \& Childress, J. F. (2013). Principles of biomedical ethics (7th ed.). New York: Oxford University Press.

Centers for Disease Control and Prevention. (2015). Common Eye Disorders. Retrieved from https://www.cdc.gov/visionhealth/basics/ced/index.html

Christiansen, C. H. (1999). Defining lives: Occupation as identity: An essay on competence, coherence, and the creation of meaning. American Journal of Occupational Therapy, 53, 547-558.

Clark, L. (2018). Women, aging, and beauty culture: Navigating the social perils of looking old. Journal of the American Society on Aging, 41(4), 104-108 
Corn, A. L, \& Lusk, K. E., (2010). Perspectives on low vision. In A.L. Corn \& J.N. Erin (Eds.), Foundations of low vision: Clinical and functional perspectives (2 $\left.{ }^{\mathrm{nd}} \mathrm{ed}.\right), 3-34$. New York, New York: AFB Press.

Crews J, Chou C, Zack M, Zhang X, Bullard K, Morse A, \& Saaddine J. (2016). The association of health-related quality of life with severity of visual impairment among people aged 40-64 years: Findings from the 2006-2010 Behavioral Risk Factor Surveillance System. Ophthalmic Epidemiology, 23(3):145-153

Csikszentmihalyi, M. (1990). Flow: The psychology of optimal experience. New York: Harper \& Row.

Evans, J. R., Fletcher, A. E., \& Wormald, R. P. L. (2007). Original Article: Depression and anxiety in visually impaired older people. Ophthalmology, 114, 283-288. https://doi.org/10.1016/j.ophtha.2006.10.006

Golden girls: How beauty therapy boosts self-esteem in care homes; Far from being a frivolity, beauty treatments can lift residents' moods and encourage a sense of individuality. (2018). The Guardian (London, England). Retrieved from http://prxusa.lirn.net/login?url=http://search.ebscohost.com/login.aspx?direct=true \&db=edsgao\&A $\mathrm{N}=$ edsgcl.541675733\&site $=$ eds-live

Goodman, J., Knotts, G., \& Jackson, J. (2007) Doing dress and the construction of women's gender identity. Journal of Occupational Science, (14)2, 100-107. DOI: $10.1080 / 14427591.2007 .9686590$

Hama et al., 1990. Hama H., Hibino E., and Fujita Y.: Attempting Emotional Revitalization through Cosmetics. In (eds): Proceedings of the 54th Meeting of the Japanese Psychological Association; June 3, 1990. Tokyo: Tokyo Metropolitan University. The Japanese Psychological Association, 1990.

Hammer, G. (2012). Blind Women's Appearance Management: Negotiating normalcy between discipline and pleasure. Gender \& Society, 26(3), 406432. https://doi.org/10.1177/0891243212438263

Hara, C. (2004). Comprehensive psychotherapy for geriatric patients with dementia: A focus on cosmetic therapy. Journal of Clinical Psychology, 22, pp. 511-519

Hayakawa, Y., Shoji, I., Kumon, H., Tokita, M., Kamata, M., \& Arao, T. (2016). Feasibility and effectiveness of a cosmetic intervention program for institutionalized older women in Japan. Preventive Medicine Reports, 4, 242-247. https://doi.org/10.1016/j.pmedr.2016.06.009

Hibino E., Yogo M., Oka C., Chikugo C., and Kadoya A. (2002). The effects of cosmetics on the emotional states of persons with depressive tendencies. In (eds): Proceedings of the 66th 
Meeting of the Japanese Psychological Association; September 26, 2002. Hiroshima University, Hiroshima. The Japanese Psychological Association, 2002.

Hirooka, K., Sato, S., Nitta, E., Tsujikawa, A. (2016). The relationship between visionrelated quality of life and visual function in glaucoma patients. Journal of Glaucoma, 25(6), 505-509. doi: 10.1097/IJG.0000000000000372

Kempen G, Ballemans J, Ranchor A, van Rens G, Zijlstra G. (2012). The impact of low vision on activities of daily living, symptoms of depression, feelings of anxiety and social support in community-living older adults seeking vision rehabilitation services. Quality of Life Research, 21(8):1405-1411

Kendrick, K., 2008. "Normalizing” female cancer patients: Look good, feel better and other image programs. Disability \& Society, 23(3), 259-269. http://dx.doi.org/10.1080/ 09687590801954042.

Kielhofner, G., Tham, K., Baz, T., \& Hutson, J. (2008). Performance capacity and the lived body. In G. Kielhofner (Ed.), Model of human occupation: Theory and application (pp.68-84). New York: Lippincott, Williams, and Wilkins

Liu, C.-J., Brost, M. A., Horton, V. E., Kenyon, S. B., \& Mears, K. E. (2013). Occupational therapy interventions to improve performance of daily activities at home for older adults with low vision: A systematic review. American Journal of Occupational Therapy, 67, 279-287. http://dx.doi.org/10.5014/ajot.2013.005512

Morey, D. (2016). Occupational Therapy in Low Vision Rehabilitation: A Road Less Traveled. Communique, (2), 10-11. Retrieved from http://prxusa.lirn.net/login?url=http://search.ebscohost.com/login.aspx?direct=true $\& \mathrm{db}=\mathrm{ccm} \& \mathrm{AN}$ $=124268611 \&$ site $=$ eds-live

Nash, R., Fieldman, G., Hussey, T., Lévêque, J., \& Pineau, P. (2006). Cosmetics: They Influence More Than Caucasian Female Facial Attractiveness. Journal of Applied Social Psychology, 36(2), 493-504.

National Eye Institute (ca. 2012) Low vision: Frequently asked questions. Retrieved from www.nei.nih.gov/lowvision/content/ know.asp

Rebeiro, K. L., \& Polgar, J. M. (1999). Enabling occupational performance: Optimal experiences in therapy. Canadian Journal of Occupational Therapy, (1), 14. Retrieved from http://prxusa.lirn.net/login?url=http://search.ebscohost.com/login.aspx?direct=true $\& \mathrm{db}=$ edsgao\&A $\mathrm{N}=$ edsgcl.200778127\&site $=$ eds-live

Schipper, H., Clinch, J., Powell, V.(1990). Definitions and conceptual issues. In: B. Spilker (Ed), Quality of life assessments in clinical trials (pp. 11-24). New York: Raven Press. 
Smith, D., \& Hudson, S. (2012). Using the Person-Environment-Occupational Performance conceptual model as an analyzing framework for health literacy. Journal of Communication in Healthcare, 5(1), 3-11. https://doi-org.prxusa.lirn.net/10.1179/1753807611Y.0000000021

van der Aa, H., Krijnen-de Bruin, E., Rens, G., Twisk, J., Nispen, R., van der Aa, H. P. A., van Nispen, R. M. A. (2015). Watchful waiting for subthreshold depression and anxiety in visually impaired older adults. Quality of Life Research, 24(12), 2885-2893. https://doiorg.prx-usa.lirn.net/10.1007/s11136-015-1032-5

Warren M. (1995). Including occupational therapy in low vision rehabilitation. American Journal of Occupational Therapy, 49(9), 857-860. http://dx.doi. org/10.5014/ajot.49.9.857

Wilcock, A. A., \& Townsend, E. A. (2014). Occupational justice. In B. A. Boyt Schell, G. Gillen, \& M. Scaffa (Eds.), Willard and Spackman's Occupational Therapy (12th ed., pp. 541-552). Philadelphia: Lippincott Williams \& Wilkins.

World Federation of Occupational Therapists. (2012). Definition of occupational therapy. Retrieved from http://www.wfot.org/AboutUs/AboutOccupationalTherapy/DefinitionofOccupationalTher apy.aspx 
APPENDIX A

Pre-Program Interview Questions 


\section{Appendix A \\ Pre-Program Interview Questions}

1. Can you tell me what type of vision impairment(s) you have?

2. Since acquiring your visual impairment, has anyone ever taught you aesthetic techniques (e.g. makeup application, skin care management, hair styling, etc.)?
a. Yes
b. No

3. Do you currently perform any aesthetic techniques on your own?
a. Yes
b. No

4. If so, what kind techniques do you perform?

5. Describe how confident you feel performing these techniques.
a. Not confident
b. Somewhat confident
c. Very confident

6. Do you currently rely on others to help you perform these techniques?
a. Yes
b. No

7. If so, how much do you rely on them?
a. Very little
b. About $50 \%$ of the time
c. More than $50 \%$ of the time
d. $100 \%$ of the time 
8. Do you feel comfortable shopping for aesthetic-related supplies at a store (e.g. makeup application products, skin management products, hairstyling products, lighting equipment, magnifying equipment, etc.)?
a. Not comfortable
b. Somewhat comfortable
c. Very comfortable

9. How satisfied are you with your self-image?
a. Not satisfied
b. Somewhat satisfied
c. Very satisfied

10. Do you feel self-conscious engaging with others because of your self-image?
a. Not self-conscious
b. Somewhat self-conscious
c. Very self-conscious

11. If you answered, "somewhat self-conscious" or "very self-conscious" for question 10, can you explain why?

12. Does your self-image make it difficult to fulfill your roles in life (e.g. family roles, peer/friendship roles, community roles, work roles, etc.)?
a. Not difficult
b. Somewhat difficult
c. Very difficult

13. If you answered, "somewhat difficult" or "very difficult" for question 12, can you explain why? 
14. How difficult does your self-image make it for you to participate in work, leisure activities, and hobbies?
a. Not difficult
b. Somewhat difficult
c. Very difficult

15. If you answered, "somewhat difficult" or "very difficult" for question 14, can you explain why?

16. Are you interested in learning new aesthetic techniques?
a. Not interested
b. Somewhat interested
c. Very interested

17. What techniques are you interested in learning during this class?

18. What challenges do you currently face when performing aesthetic techniques?

19. What do you hope to gain from this class?

20. How would you like your notes from the class - electronically, in large print, or in braille? 


\section{APPENDIX B}

Post Program Interview Questions 


\section{Appendix B}

\section{Post-Program Interview Questions}

1. After participating in the class, do you see yourself performing aesthetic techniques moving forward?
a. Yes
b. No

2. If so, which aesthetic techniques do you see yourself performing?

3. Describe how confident you feel performing these techniques.
a. Not confident
b. Somewhat confident
c. Very confident

4. After participating in the class, do you anticipate relying on others to help you perform aesthetic techniques?
a. Yes
b. No

5. If so, how much do you anticipate relying on them?
a. Very little
b. About $50 \%$ of the time
c. More than $50 \%$ of the time
d. $100 \%$ of the time

6. After participating in the class, do you feel comfortable shopping for aesthetic-related supplies at a store?

a. Not comfortable 
b. Somewhat comfortable

c. Very comfortable

7. After participating in the class, how satisfied are you with your self-image?
a. Not satisfied
b. Somewhat satisfied
c. Very satisfied

8. After participating in the class, do you feel self-conscious engaging with others because of your self-image?
a. Not self-conscious
b. Somewhat self-conscious
c. Very self-conscious

9. After participating in the class, do you feel comfortable fulfilling your roles in life (e.g. family roles, peer/friendship roles, community roles, work roles, etc.)?
a. Not comfortable
b. Somewhat comfortable
c. Very comfortable

10. After participating in the class, how difficult does your self-image make it for you to participate in work, leisure activities, and hobbies?
a. Not difficult
b. Somewhat difficult
c. Very difficult

11. Describe if the class impacted your satisfaction with your self-image. 
12. Did this class address the challenges you faced when previously performing aesthetic techniques? If so, how?

13. In the initial interview, you were asked what you hope to gain from this class. You previously answered “......". What did you feel you gained from this class?

14. Describe which aesthetic techniques you are interested in learning that this class did not address.

15. Do you have any feedback and/or recommendations on how we can improve this class for future semesters at the Braille Institute? 
APPENDIX C

Supply List 


\section{Appendix C}

\section{Supply List}

\begin{tabular}{|c|c|c|}
\hline Supplies & $\begin{array}{l}\text { Estimated cost } \\
\text { *Will depend on desired } \\
\text { quality of products and/or } \\
\text { if participants already } \\
\text { have them. }\end{array}$ & Where to shop for supplies \\
\hline $\begin{array}{l}\text { Makeup products (e.g. primer, } \\
\text { foundation, concealer, blush, mascara, } \\
\text { eye-liner, eyeshadow, lipstick, lip-gloss, } \\
\text { bronzer, etc.) }\end{array}$ & $\begin{array}{l}* \text { Will depend per person } \\
(\$ 10-\$ 50+)\end{array}$ & $\begin{array}{l}\text { Target } \AA \text {, Wal-Mart } \AA \text {, CVS } \AA \text {, } \\
\text { Walgreens }{ }^{\circledR} \text {, Ulta } \AA \text {, Sephora }{ }^{\circledR} \text {, } \\
\text { Amazon } \AA \text {, Dollar Store } \AA\end{array}$ \\
\hline $\begin{array}{l}\text { Makeup application and removal } \\
\text { products (e.g. makeup brushes, makeup- } \\
\text { remover wipes) }\end{array}$ & $\begin{array}{l}\text { *Will depend per person } \\
(\$ 10-\$ 30+)\end{array}$ & $\begin{array}{l}\text { Target } \AA \text {, Wal-Mart } \AA \text {, CVS } \AA \text {, } \\
\text { Walgreens } \AA \text {, Ulta } \AA \text {, Sephora }{ }^{\circledR} \text {, } \\
\text { Amazon } \AA \text {, Dollar Store } \AA\end{array}$ \\
\hline $\begin{array}{l}\text { Skin care management products (e.g. } \\
\text { facial cleanser, toner, moisturizer, } \\
\text { sunscreen with SPF, face masks) }\end{array}$ & $\begin{array}{l}\text { *Will depend per person } \\
(\$ 10-\$ 40+)\end{array}$ & $\begin{array}{l}\text { Target } \AA, \text { Wal-Mart } \AA \text {, CVS } \AA \text {, } \\
\text { Walgreens } \AA \text {, Ulta } \AA \text {, Sephora } \AA \text {, } \\
\text { Amazon } \AA \text {, LUSH } \AA \text {, Dollar } \\
\text { Store } \AA\end{array}$ \\
\hline $\begin{array}{l}\text { Hairstyling tools and products (e.g. brush, } \\
\text { comb, hairspray, dry shampoo, serums, } \\
\text { rollers, hair straightener, blow-dryer, } \\
\text { curling iron, hair clips, headbands) }\end{array}$ & $\begin{array}{l}\text { *Will depend per person } \\
(\$ 10-\$ 80+)\end{array}$ & $\begin{array}{l}\text { Target } \AA, \text { Wal-Mart } \AA \text {, Ulta } \AA \text {, } \\
\text { CVS } \AA, \text { Walgreens } \AA \text {, Amazon } \AA \text {, } \\
\text { Sally Beauty Supply } \AA \text {, Dollar } \\
\text { Store } \AA\end{array}$ \\
\hline Lighting equipment, magnifying mirrors & $\begin{array}{l}* \text { Will depend per person } \\
(\$ 10-\$ 30)\end{array}$ & $\begin{array}{l}\text { Target } \AA \text {, Wal-Mart } \AA \text {, Home } \\
\operatorname{Depot} \AA \text {, Lowes } \AA\end{array}$ \\
\hline Makeup products/brushes holder & $\begin{array}{l}\text { *Will depend per person } \\
(\$ 10-\$ 20)\end{array}$ & $\begin{array}{l}\text { Target } \AA \text {, Wal-Mart }{ }^{\circledR}, \text { Ulta } \AA \text {, TJ } \\
\text { Maxx }{ }^{\circledR} \text {, Marshall’s } \AA \text {, Ross } \AA\end{array}$ \\
\hline
\end{tabular}


APPENDIX D

Aesthetic Techniques Program Resource Binder 


\section{Appendix D}

Aesthetic Techniques Program Resource Binder

*All the information from this binder were given to students in Braille, in enlarged print, as an audio-recorded format, or electronically via email. The contents of this binder were also given as a resource to the volunteer who took over in the next class session.

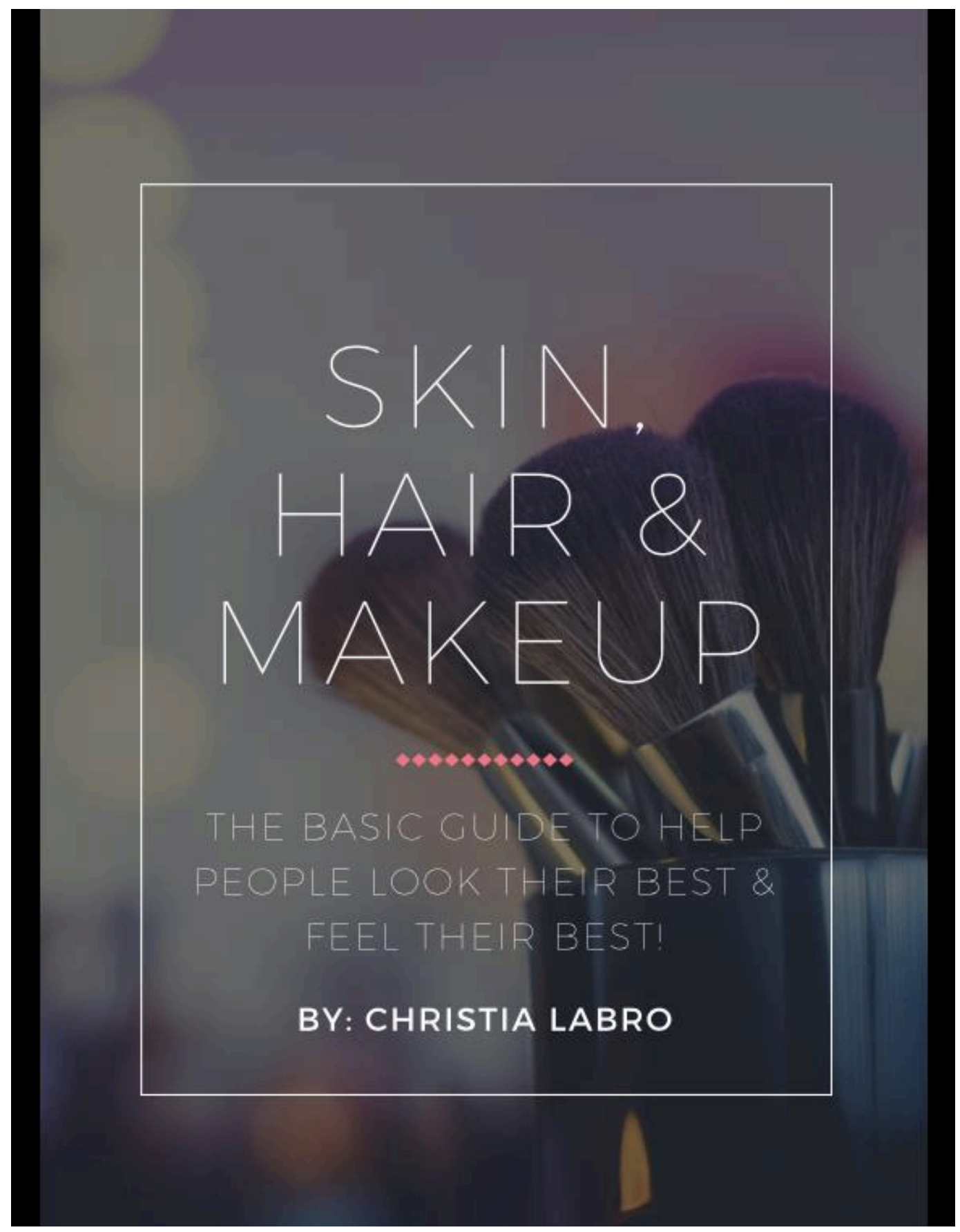




\section{The Ultimate Guide to Skin Care}

Let's talk about skin care! You may not think too much about your skin care routine, but it is very important that you should! Your skin is one of the largest organs in your body and it works hard every day to protect our bodies from harmful elements, therefore, having a good skin care routine is important. Having a good skin care routine also makes you look more presentable to the public because it makes a statement that you take care of yourself.

\section{WHY GOOD SKIN CARE IS IMORTANT}

(source: huffpost.com/entry/how-to-identify-your-skin-type)

1) Our skin sheds itself daily. You may think that your skin is healthy today, but did you know that your skin cells shed just about every minute of every day? This means that the healthy skin you have today will be shedding tomorrow, so it's important to take care of your skin every day.

2) All skin types are different. Perhaps you may have a friend who doesn't have a skin care routine and her skin looks great. Although that is great for her, your skin type may be totally different. Because of this, your skin may require more care than the next person. For this reason, a daily skin care routine is important. If you know your skin type - whether you have normal skin, tend to be more dry, more oily, have a combination of both, have more sensitive, or have acne-prone skin, then it is always a good idea to ask a skin care expert (like the people we will encounter at the mall) for suggestions on what types of products to use for your skin. If you aren't sure what type of skin you have, here are some tips.

\section{a. Normal skin}

i. Normal skin would refer to skin that doesn't experience any kind of excessive skin conditions. Normal skin types have a great balance of oil and moisture. You may experience some shininess by the end of the day, but only around the center of your face.

ii. I recommend still using products like a facial cleanser, moisturizer with SPF (sun) protection, and a toner for your daily skin care routine.

\section{b. Oily skin}


i. A good indicator to determine if you have oily skin is the way your face feels soon after it's been washed. People that have oily skin, even without using any moisturizer, would feel an obvious oiliness, particularly across their forehead, down the center of their nose, their shin, and sometimes extends down to the chest area.

\section{c. Dry skin}

i. A good indicator of having dry skin is once you've washed your face, your skin tends to feel "very very tight" if you don't moisturize within an hour or two after cleansing. The skin around your eyes and mouth would feel very tight and uncomfortable without the use of a moisturizer. Those with dry skin might also experience flakiness.

\section{d. Acne-Prone skin}

i. What is happening in acne-prone skin is that your skin is marked by regular breakouts and clogged pores. If you only have pimples on rare occasions, then I don't think you have to consider yourself acne-prone. But if you get clogged pores and pimples regularly, then I think it's fair to say you are acneprone.

\section{e. Sensitive skin}

i. Sensitive skin is usually marked by how it reacts to both topical products and factors like the sun's UV rays. Usually if you have really sensitive skin, you may be prone to redness in the face. You might be super-sensitive to the sun in addition to reacting to topical products. Skin can also become sensitized over time as a result of overusing products that are too harsh.

\section{f. Combination skin}

i. The most common combination skin type refers to skin that gets a little oily in the "T-zone" area (which is the across forehead and along the nose, hence the " $T$ " shape) whereas other areas of the skin are dry. Other combination skin types are a combination of those skin types I mentioned above such as acne-prone and sensitive skin, or acne-prone and dry, or acne-prone and oily. You get the idea. Everyone's skin is different. 


\section{A GOOD SKIN CARE ROUTINE}

1. Makeup remover - Remove all makeup with a makeup remover and toss it out once you are done. If you don't wear makeup, skip this step.

2. Facial cleansing - Facial cleansers clean your face to remove dirt, oil, makeup, and other excess germs. Look for one that is suitable for your skin type. Wash your face with a facial cleanser that works well with your skin type. If you have long hair, tie it back or wear a headband to avoid getting your hair wet. Stand over the sink and wet your face with warm water. Then squeeze a small amount of cleansing product on your fingertips. Apply the product evenly on your face, then gently massage the product all over your face to produce a lather. You can add more water to your face if you need to. Massage the product all over your face for about 1 minute. You may choose to avoid the eye area completely to avoid irritating your eyes or you can keep your eyes closed the entire time. Rinse your face with warm water to remove all the product. Gently pat your skin dry with a clean towel. Remember too not be too rough when drying your skin. This will damage the look of your skin later on.

3. Toner (optional) - A face toner helps remove excess dirt, traces of oil and makeup, and helps control acne. It also helps shrink the appearance of pores. Apply the toner on a cotton round or cotton ball and apply it all over your face, especially areas where you tend to have acne. You can repeat this step once more to make sure you reached your entire face. Let it dry before you apply moisturizer.

4. Moisturizer - Apply a small amount of moisturizer on your fingertips then apply the product evenly all over your face using an upward motion. This will help prevent future wrinkles and keep your skin young looking. Go over your face once more with just your fingers to make sure you've applied the product all over.

5. SPF - Use an SPF product during the day to protect your face from the sun, aging, and prevent skin cancer. Some moisturizers already have SPF on it so look for a moisturizing product that does.

6. Lip balm - Wear lip balm to moisturize your lips. This is very important because lips have very sensitive skin and can be damaged easily. You can also use petroleum jelly on your lips instead of a lip balm. Some lip balms 
have slight color to them too. You can choose one that is clear or one that has color, whichever you prefer.

7. Exfoliator (optional) - Exfoliate your skin no more than once a week. Exfoliators usually have hard grains that feel like sugar that are meant to scrub the area to help remove dead skin cells and dirt. You do not have to do this, but it will help your skin to look very clean, fresh, and reduce acne. Wet your face with warm water and apply a small amount of product on your fingertips then apply that all over your face. Massage your face with the product then rinse off with warm water. Pat your skin dry and apply a moisturizer afterward.

8. Facial masks (optional) - Applying a facial mask once a week will help hydrate your skin, help improve the appearance of pores, and help your skin look plump and healthy. There are different kinds of face masks out there, sheet masks and the clay/cream consistency ones are the most popular.

a. To use a clay/cream mask: apply the face mask all over your face using your fingertips or a brush. Leave the mask on for however long the directions says. Rinse the mask off using warm water. Pat your skin dry and use a moisturizer afterward.

b. For sheet masks, they have cutout openings for your eyes, nostrils, and mouth. Line the mask along your face and leave it on for however long the direction says. You do not have to rinse your face with water afterward. Simply massage the remaining product left on your face until your skin dissolves the product. Or you can use a clean towel to pat dry the excess liquid remaining if you wish

9. Facial cleansing brush (optional) - Rather than using your hands to wash your face, you can also try using a facial cleansing brush. This brush is usually round-shaped and has gentle bristles to help with exfoliating the skin. I absolutely love using this in my personal skin care routine.

10. Jade roller (optional) - A jade roller is a tool that helps minimize puffiness and swelling in your face. Puffiness in your face occurs because of the salty food that we eat. This tool is really fun to use because it feels like you are giving your face a light massage. Use this along with your moisturizer. Start from the bottom of your face and work your way up. You can also place it in a Ziploc bag and leave it in the refrigerator overnight so you can use it cold. Using it cold has amazing benefits to your skin such as increasing blood flow and circulation. Give it a try! 
Now that you are familiar with all the different types of products, let's create your own personalized skin care routine. Personally, my "must-haves" for a daily skin care routine includes using a makeup remover, facial cleanser, moisturizer, SPF, lip balm, and then a face mask once a week. You can add other products I mentioned, but it is good to start with those.

IMPORTANT TIPS FOR SKIN CARE:

1. Label your products with tactile markings or in braille. You can also label them numerically to help you remember the order in which you use the products. Keep these products by the sink or in the bathroom cabinet to help you remember to perform your skin care routine. It's important to perform a skin care routine at least once a day. I like to do a light routine in the morning to wake my skin up after a good night of sleep. But most importantly, I do thorough routine at night after a long day because that is when I have built up dirt, sweat, and makeup I need to remove.

2. Don't neglect your neck. Keep it moisturized and apply SPF on it too.

3. Eat and drink healthy.

4. Drink lots of water to hydrate your body and your skin.

5. Manage your stress. Stress can cause hormones in our body to react and it will affect how our skin looks.

6. Do not drink too much alcohol or caffeine, they dehydrate your skin.

7. Get enough sleep.

8. Make sure you are getting enough exercise.

9. Shower or take a bath once a day. This helps get rid of dirt, sweat, and germs that your body may have accumulated throughout the day. 10. Go to a dermatologist to have your skin checked every couple of years to make sure you don't have any skin cancer or other issues.

COMMON STORES THAT SELL SKIN CARE PRODUCTS

- Affordable stores: Walmart, Target, CVS, Walgreens, Amazon, Ross, TJ Maxx, Marshall's, DAISO

- Higher end stores: LUSH, Sephora, The Body Shop, L'Occitane, Kiehl's 


\section{Drugstore/Affordable Alternatives for Skin Care Products}

You could buy these products at CVS, Walgreens, Walmart, or Target. Some of them may only be available online, but I included a wide range of products to choose from! Remember to get the products that are suitable for your skin type.

Also, remember these steps:

Step 1 - makeup remover wipes (only if you have makeup on)

Step 2 - facial wash

Step 3 - toner

Step 4 - moisturizer with sunscreen

Step 5 - lip balm.

*Face masks are only intended to use 1-2x a week, same with your home sugar scrub!

- Makeup Remover Wipes

- Neutrogena Makeup Remover Cleansing Towelettes

- Aveeno Ultra-Calming Cleansing Makeup Removing Wipes

- Burt's Bees Facial Cleansing Towelettes

- Yes to Argan Oil 2-in-1 Cleansing and Moisturizing Facial Wipes

- Facial wash:

- CeraVe Facial Cleanser (dermatologist recommended, there are a few different kinds for each skin type, choose whichever is most suitable for your skin)

- Cetaphil Daily Facial Cleanser (dermatologist recommended, there are a few different kinds for each skin type, choose whichever is most suitable for your skin)

- Neutrogena Oil-Free Acne Wash

- Neutrogena Ultra Gentle Hydrating Cleanser

- Aveeno Absolutely Ageless Nourishing Cleanser

- Olay sensitive fragrance-free facial cleanser (best for sensitive skin)

- Burt's Bees Brightening Daily Facial Cleanser

- Up \& Up (Target brand) deep cleanser cream (good for all skin types)

- Simple Sensitive Skin Experts Foaming Cleanser 
- Toner:

- Garnier SkinActive Micellar Cleansing Water (best for all skin types)

- Botanics All Bright Cleansing Toner (best for all skin types)

- Dickinson's Original Witch Hazel Toner (best for sensitive and dry skin)

○ Thayer's Witch Hazel Alcohol-Free Toner (best for normal and oily skin)

- Moisturizer (some of these also have sunscreen in them)

- CeraVe (dermatologist recommended, there are a few different kinds for each skin type, choose whichever is most suitable for your skin, some also have sunscreen in it)

- Cetaphil (dermatologist recommended, there are a few different kinds for each skin type, choose whichever is most suitable for your skin, some also have sunscreen in it)

- Neutrogena Hydro Boost Gel Moisturizing Sunscreen Lotion (perfect to put under makeup, light and non-greasy)

- Olay Regenerist Whip Face Moisturizer with sunscreen (best for antiaging)

○ Pond's Rejuveness Anti-Wrinkle Daily Moisturizer with Sunscreen SPF 30

- Burt's Bees Daily Moisturizing Cream (best for sensitive skin)

- Aveeno Positively Radiant Daily Moisturizer with sunscreen (great for someone with dark spots who wants to brighten the skin)

- Garnier Skin Active Balancing 3-in-1 face moisturizer with green tea (best for acne skin)

- Pond's Dry Skin Cream (best for very dry skin)

- Yes To Cucumbers Cooling Moisturizer (best for sensitive skin)

- Lip care:

- Vaseline petroleum jelly (my all time favorite, super cheap and lasts very long)

○ EOS lip balm

- Aquaphor Lip Repair lip balm

- Burt's Bees Beeswax lip balm

- Nivea Moisture Essential Lip Care 
- Carmex Classic lip balm

- Chapstick lip balm

- Palmer's Cocoa Butter Lip Balm

- Face masks

- Pacifica Wake Up Beautiful Super Hydration Sleep Mask

- Neutrogena Clear Pore Cleanser/Mask

- Yes to Tomatoes Detoxifying Charcoal Mud Mask

- L'Oreal Paris Skincare Revitalist Triple Power Intensive Overnight Face Mask

- Queen Helene Masque Mint Julep

○ St. Ives Soothing Oatmeal Hydrogel Eye Mask 


\section{All natural lip, face, \& body scrub}

Ingredients

- 5-6 teaspoons of white sugar

- 5-6 teaspoons of raw cane sugar

- 1 teaspoons honey

- 2 teaspoons olive oil

- Juice of $1 / 2$ of a lemon

** You can tweak these ingredients to your liking. Adding more sugar creates more exfoliation. Adding more olive oil or honey creates more moisturizing. Add or subtract whatever you like!

What all these ingredients do for your skin

- Sugar is a natural exfoliator which helps to remove dead skin from areas of your body.

- Olive oil softens the skin and helps fight against environmental skin damage.

- Lemon is a natural antioxidant that helps neutralize the skin, boost skin cell production, helps with blemish control, and brighten your skin.

- Honey is great for acne treatment and prevention. It's full of anti-oxidants which helps to slow down aging. It is also useful if you have any sunburns. And finally, it is extremely moisturizing and soothing so it adds a natural glow to your skin.

Directions

1. Apply sugar scrub on dry, clean skin.

2. Massage the sugar scrub on your skin for about 2-3 minutes.

3. Rinse off the scrub and pat dry with a clean towel.

4. Now you have smooth, bright, clean skin!

Tips to Remember

- The scrub is only intended for a month use. Throw away remaining scrub and create a new batch if you wish.

- Store the scrub in a dry place. Room temperature is okay. Do not put it in the refrigerator or else it will harden. 


\section{Makeup Application}

Let's face it. Everyone wants to look good. Everyone wants to look presentable when they go out in public. Makeup is meant to enhance the beauty you already have, not change you completely. You can express yourselves through the use of makeup. You can put on eyeshadow or lipstick colors that showcase your mood, personality, or match the outfit you are wearing. Makeup is meant to be fun, artistic and expressive! However, I know that looking your best is a bit more challenging when you have a vision impairment, especially if you cannot see the products you are using or the end result of your makeup application. But I am here to teach you the basics of makeup application and different ways you can still apply makeup with a little bit of practice.

To get started, keep in mind that there is a good relationship about how skin feels and looks. It is important that you have a good skin care routine as well. Makeup applies better if you take good care of your skin. It is also good to know what type of skin you have to make sure you are using the right products on your face. Let's talk about skin before we dive into makeup (go over skin care handout)...

Now that we got that squared away, let's talk makeup.

Discussion: Who here already puts on makeup? Can you tell me what kind of makeup you're familiar with and what you put on? I want to try and teach you what you want to know. So, what are some things you want to learn in this class?

\section{BASIC MAKEUP PRODUCTS AND HOW TO APPLY THEM}

*You can always skip a step if it is too elaborate for you or if you prefer lighter makeup.

Primer - Face primer is used to help makeup last longer, smooth the skin's surface, and even out the skin tone. Apply a face primer before you apply foundation. Apply a small amount all over your face.

Foundation - Finding the right foundation can be tricky. It is always good to ask a cosmetician at the store to help you find the right color for your skin. To apply liquid foundation, shake the bottle and use your index finger to apply tiny dots on your forehead, nose, cheeks, and chin. For a powder foundation, apply it using a 
sponge to each area of your face like I mentioned above. We will practice applying foundation using your fingertips, brushes, and sponges, but remember to apply it against gravity in an upwards motion. Go over it twice to make sure everything it blended.

Concealer - Concealer is used to conceal blemishes and eye bags. Like foundation, it is always good to ask a cosmetician at the store to help you find the right color for your skin. Apply concealer to the areas where you have blemishes and underneath your eyes to cover eye bags. If you are unsure where your blemishes are, use your fingertips to feel any areas that are uneven on your face. Blend this out using fingertips, a brush, or sponge. Repeat this once more to make sure it is all blended. You can also use a lighter color concealer to highlight certain areas of the face. Usually this is paired with contouring. We will get to highlight and contouring next.

Highlight and contouring - This step is more elaborate. Feel free to skip this one if you like. Highlight and contouring is meant to sculpt your face by enhancing your cheekbones, making your face look slimmer, create a more glamorous look, and it looks great for pictures. You can also do this in a more neutral way just by using bronzer and light powder or a more dramatic way using liquid products and powders

- Neutral look (using powders only) - Use a light powder (slightly lighter color than your skin tone) and apply it underneath your eyes, on your T-zone area (on your forehead and down the center of your nose), and middle of your chin. Use a bronzer (powder that is slightly darker than your skin tone) and apply it underneath your cheekbones, hairline, and jawline. Finish off with a little blush on the apples of your cheeks and highlighter on top of your cheekbones.

- Dramatic look (using liquid products and finishing powders) - You will need two liquid concealers or foundations. One that is a slightly lighter color than you skin and one that is slightly darker than your skin. You will also need a finishing powder. After you've applied foundation all over your face, take the lighter concealer or foundation and apply it to your t-zone area (on your forehead and down the center of your nose), underneath your eyes until above your cheekbones, above your jawline, middle of your upper lip, middle of your chin. Blend and double-blend all of that separately. A 
beauty blender is great for this and does a better job than brushes. Then, you will take the darker concealer or foundation and apply it to the sides of your nose, right under your cheekbones, hairline, and jawline. Blend like you did earlier. You can go over the areas you highlighted with a light powder and the areas you contoured with a bronzer if you wish. Apply a finishing powder to help all the products stay in place. Finish off with a little blush on the apples of your cheeks and shimmering highlight on the top of your cheekbones, upper lip, and on the tip of your nose.

Blush - Apply a rosy-color blush at the apples of your cheeks toward your ears.

Highlighter - This product creates a shimmery, sun-kissed glow on your skin. It is usually applied above the cheekbones and on your upper lip line, but you can apply it wherever you like. You can use your fingers or a brush to apply it. Remember that a little product goes a LONG way.

Eyeshadow - You can use any color and apply it on your eyelid. You can add a darker color on the outer corner of our eye for a smoky look. Use a clean finger or brush to blend the eyeshadow so there are no harsh lines.

Eyeliner - Apply a non-liquid eyeliner just right above your eye line. You can use your finger as a guard to know when to start and stop.

Mascara - Slightly open your eyes, raise your eyebrows, and apply mascara on your eyelashes starting from the base to the tip. You can use an index card or a mascara guard to cover your eyelids to avoid getting product on your lids. Be careful not to poke your eye with the mascara wand. If you prefer to close your eyes during this process, you may do so. You can use your fingers as a starting guide where to place the mascara wand.

Eyebrows - You can use a stencil to help you. You can shop for these online. You can match what face shape you have with which eyebrow look is best for you. Or you can choose whichever shape you like. Place your index finger straight alongside your nose to the top of your brow line - this is the start of your eyebrow. Place your index finger alongside the end of your eye and angle it slightly - this is the end of your eyebrow. Once you have determined which 
stencil to use, line up the widest end of the stencil to the beginning of the brow line and line up the thinnest part of the stencil to the end of your eyebrow. Once you are satisfied with the placement of your stencil, you can use eyebrow makeup to softly fill in the area. After, use an eyebrow brush to gently groom the bros and blend the color for a more natural appearance. The trick is to PRACTICE, PRACTICE, PRACTICE!!!

Lipstick - You can start by dabbing a bit of color on your finger and apply it to your lips. You can also use a lip brush instead of the actual tube or the actual tube if you wish. Start on the lower lip and left or right side then toward the center then repeat on the other side. Then on your top lip, start on one side toward the center following the outline of your lip, then repeat on the other side. Another tip is using a cold lip brush or disposable lip brush so you can feel the coldness to where you are applying. Blot with a tissue paper to remove excess amount.

Lip gloss - You can wear lip gloss by itself or wear it over lipstick. You really only need very little to get the glossy effect!

Voila! Keep practicing every day so you can get used to the whole routine. If you have someone at home with you, have them check once you are done to make sure you blended everything.

Always remember to wipe your makeup off with a makeup remover wipe at the end of the day and wash your face with a gentle cleanser.

\section{ADDITIONAL TIPS}

- Do not sleep with your makeup on! Remove your makeup with a makeup remover wipe and/or wash your face with a facial cleanser before you go to bed.

- Wear a headband to keep your hair back so makeup doesn't get on it.

- Wear a robe over your clothes or put a towel on top of your shirt to avoid getting makeup on your clothes.

- Sit down when you put makeup on.

- If you have low vision, improve the lighting of your area to best suit your needs. Sitting in front of an area that has good or natural lighting from the sun will help you see better. 
- Label your products with tactile markings or braille. Organize them using makeup storage boxes, trays, or cabinets.

- Keep your products and brushes in the same spot so you always know where everything is located.

- Wash makeup brushes with diluted soap or shampoo and conditioner because build-up of makeup, sweat, and bacteria can accumulate. Allow them to dry completely before using them.

- Makeup also expires. Be sure to throw away makeup after one year and replace it. Certain products like mascara and eyeliner can cause infection if used after a year.

COMMON STORES THAT SELL MAKEUP PRODUCTS

- Affordable stores: Walmart, Target, CVS, Walgreens, Amazon, DAISO

- Higher end stores: Sephora, MAC, Ulta, The Body Shop, L'Occitane 


\section{Hair Care \& Styling}

\section{ORGANIZATION AND LABELING}

- Label products with tactile markers or braille.

- Use storage containers for small items like hair pins, hair ties, clips, accessories.

- Label shower items for easy identification.

HOW TO KEEP HAIR HEALTHY

- Avoid smoking, this thins out your hair

- Manage your stress because stress causes hair to fall out

- Drink a lot of water

- Eat and drink healthy

- Avoid caffeine and sodas because these are bad for your hair - it dehydrates you

- Massage your scalp to improve hair growth, use fingers or a scalp massager

- Chlorine is bad for your hair. If you go swimming a lot, wear a cap or rinse hair before and after you swim.

- Use warm or cold water to wash your hair. Hot water damages hair.

- Wash your hair whenever it feels dirty or oily, but avoid washing your hair every day. Use dry shampoo in between washing or when you are in a rush. You simply shake the can and spray this on the oily parts of your hair. Use your hands to ruffle through where you sprayed to remove the white powder residue.

- Use the right kind of shampoo and conditioner for your hair type.

- Hair is MOST fragile when it is wet so use a wide toothcomb to comb your hair or a soft bristle brush. Start from the ends of the hair and work your way up. Do not rip your hair when you comb, take your time.

- If you have psoriasis or have dandruff, one tip I learned is to wash your hair with a 1:3 mixture of apple cider vinegar and water and use a men's comb to comb through your scalp to remove the flakiness and dead cells. You simply do this in between shampooing and conditioner about $2 x /$ week. This "resets" your hair for the week and helps your scalp produce less flakiness.

STYLING PRODUCTS

- Hairspray or gel - These are helpful to keep hair in place when styling 
- Hair ties or scrunchies - Do not tie hair with plastic or rubber ties. Use a soft tie to avoid breakage.

- Rollers - These are safer to use than curling iron and it eliminates high heat which can be damaging. Rollers come in different sizes, the smaller the rollers, the tighter the curls.

- Hair accessories - Hair accessories are a fun addition to styling hair. These come in many forms.

- Hair color - There are different ways you can achieve colored hair. You can go to a salon (although this may be pricey), use box dye, or use a temporary spray dye. Just remember that you do have to maintain the color and use shampoo for colored hair.

- Hair serums - Hair serums or hair oils protect the hair from damage and infuse nutrients into your hair. They also decrease the amount of frizziness in your hair. Avoid putting them on your scalp since this will make your hair oily. Serums or oils are great to use before using a blow dryer or heated appliance to style your hair. You can also just put them on your hair and let your hair air dry.

\section{COMMON STORES THAT SELL HAIR PRODUCTS}

- Affordable stores: Walmart, Target, CVS, Walgreens, Amazon, Ross, TJ Maxx, Marshall's, Sally Beauty Supply Store

- Higher end stores: LUSH, Sephora, ULTA, Kiehl's, or any salon 


\section{Apple Cider Vinegar Mixture}

Apple cider vinegar benefits the hair and scalp in many ways.

- It helps restore the natural $\mathrm{pH}$ level of the scalp

- It prevents moisture loss from the scalp and boost its function which helps keep the hair healthy, shiny, and soft

- It gives your scalp a deep clean and helps remove residue from the build-up of styling products and conditioner from your hair which can make it look dull and lifeless

- It has nutrients which can stimulate hair follicles and remove dead skin cells to promote hair growth

- It makes your hair smoother so it's an effective way to get tangle free hair without using a conditioner

- It also helps if you're trying to get your hair straighter without using heat

- It helps tackle dandruff by destroying the dandruff-triggering fungi that clogs hair particles

How to create apple cider vinegar hair mixture/Directions for using it on your hair:

- Mix one part apple cider vinegar and 3 parts water

- Store it in a plastic container or spray bottle and leave it in your shower

- Shake the mixture each time before using it

- Apply it directly on the scalp. Massage your scalp and leave it for about 15 minutes. Avoid getting it on your eyes.

- Use it after shampooing and before conditioning your hair.

- Or simply use it by itself. Massage your scalp and leave it on for about 15 minutes. Then rinse off.

- You can add drops of lavender oil, cedarwood oil, or tea treeoil to help with the smell. These oils are also good for stimulating hair growth. You can find these at Sprouts market.

- Your classmate used a mixture of lavender and cedarwood oil to help with hair growth. You can also try this at home!

Other great uses for apple cider vinegar

- Can help brighten the skin and help with oily skin 
- Mix equal parts apple cider vinegar and water to make a homemade toner. Put the mixture on a cotton pad and apply to the area.

- Can help with breakouts and pimples

- Dip a q-tip or cotton bud into an apple cider vinegar and water solution. Apply it on the area and leave it overnight.

- Helps get rid of stains, teeth discoloration, and kill unwanted bacteria to freshen breath.

- Mix 1 part of apple cider vinegar and 3 parts water and gargle with it. Use as a daily mouthwash

- Can help restore the strength of brittle nails and is effective in treating fungal nail infections that cause discoloration to create nails that are nice and bright.

- Mix 1 part of apple cider vinegar and 1 part of water. Soak your finger nails for 20 minutes, then rinse off.

o Do this a few times a week

- Helps with bruise healing by its anti-inflammatory properties (decreases swelling and improve blood circulation to the area)

- Use as a bath detox to help ease muscular aches and pains and help fight cellulite

- Helps with stings, sunburns, age spots, and warts

- Mix 1 part apple cider vinegar and 1 part water. Put the mixture on a cotton pad and apply to the area. Rinse off after 15 minutes.

- Helps with athlete's foot, smelly feet, and rough feet.

- Soak your feet in equal parts warm water and apple cider vinegar. Rinse off and dry.

Apple Cider Vinegar brand I like to get

- Bragg's (Raw Unfiltered Apple Cider Vinegar)

- Can find these at any grocery store

- Around 3-5 dollars 


\section{Braille Institute Library AudioBooks on Beauty and Self- Care}

*Some of these books may not be available in the talking book version. However, they are available on the BARD app. Just ask Julius or any library volunteer to help you out!

\begin{tabular}{|c|c|c|}
\hline KlasID & Title & Author \\
\hline DB054931 & $\begin{array}{l}\text { The Perricone } \\
\text { Prescription: a } \\
\text { physician's twenty-eight } \\
\text { day program for total } \\
\text { body and face } \\
\text { rejuvenation }\end{array}$ & Perricone, Nicholas \\
\hline DB053662 & $\begin{array}{l}\text { The wrinkle cure: unlock } \\
\text { the power of } \\
\text { cosmeceuticals for } \\
\text { supple, youthful skin }\end{array}$ & Perricone, Nicholas \\
\hline DB010612 & $\begin{array}{l}\text { Beauty for the mature } \\
\text { woman }\end{array}$ & Seiffert, Dorothy \\
\hline DB014563 & $\begin{array}{l}\text { Between you and me: a } \\
\text { sensible and } \\
\text { authoritative guide to } \\
\text { the care and treatment } \\
\text { of your skin }\end{array}$ & Parrish, John A. \\
\hline DB094651 & $\begin{array}{l}\text { Put your best face } \\
\text { forward: the ultimate } \\
\text { guide to skincare from } \\
\text { acne to anti-aging }\end{array}$ & Lee, Sandra \\
\hline DB070204 & $\begin{array}{l}\text { What's age got to do } \\
\text { with it? Living your } \\
\text { healthiest and happiest } \\
\text { life }\end{array}$ & McGraw, Robin \\
\hline
\end{tabular}




\begin{tabular}{|c|c|c|}
\hline DB073317 & $\begin{array}{l}20 \text { years younger: look } \\
\text { younger, feel younger, } \\
\text { be younger! }\end{array}$ & Greene, Bob \\
\hline DB021595 & $\begin{array}{l}\text { Beauty begins at forty: } \\
\text { how to look your best for } \\
\text { a lifetime }\end{array}$ & Coffey, Barbara \\
\hline DB022612 & $\begin{array}{l}\text { How to clear up your } \\
\text { face in } 30 \text { days }\end{array}$ & Zizmor, Jonathan \\
\hline DB031540 & $\begin{array}{l}\text { The new medically based } \\
\text { no-nonsese beauty book }\end{array}$ & Chase, Deborah \\
\hline DB045578 & $\begin{array}{l}\text { Beauty Lab: how science } \\
\text { is changing the way we } \\
\text { look }\end{array}$ & Dawson, Mildred \\
\hline DB056378 & $\begin{array}{l}\text { One hundred one foot- } \\
\text { care tips for people with } \\
\text { diabetes }\end{array}$ & Ahroni, Jessie H. \\
\hline DB021229 & Women coming of age & Fonda, Jane \\
\hline DB019220 & $\begin{array}{l}\text { Working out: the total } \\
\text { shape-up guide for men }\end{array}$ & Hix, Charles \\
\hline
\end{tabular}




\section{UTC La Jolla Stores for Shopping Trip Week}

The purpose of the shopping trip experience is to increase a student's comfort level in shopping, specifically by interacting with store employees to gain specific recommendations of products that would be suitable for them as well as trying on the actual products.

These are the stores that we visited during the shopping trip week. L'Occitane and The Body Shop are the two stores who went above and beyond for our students and would like to continue working with us. The rest of the stores are aware of Braille Institute and are also very welcoming/open to us going there.

- L'Occitane (Has braille on their product packaging)

○ Manager: Kristin Miller

o Phone: (858) 638-8160

- The Body Shop

- Manager: Gabrielle Murray

○ Email: store.manager1277@thebodyshop.com

- Kiehl's

- Manager: Colleen Gallagher

- Email: cgallagher@kiehl-usa.com

○ Phone: (858) 455-9720

- LUSH

○ Manager: Kayla

○ Email: utcsandiegomanager@lush.com

- Sephora

o Store Director: Ammo

○ Email: sephora.universitytownecenter@sephora.com 


\section{APPENDIX E}

\section{Braille Institute San Diego Presentation}


Appendix E

Braille Institute Presentation

Enhancing Quality of Life of

People with Visual Impairments

Through Aesthetic Techniques

By: Christia Labro

Doctor of Occupational Therapy Student

at the University of St. Augustine for Health Sciences

\section{Background on Vision Loss}

- Vision loss affects roughly 285 million people in the world

- Vision loss is associated with psychosocial consequences

- Decreased morale

- Depression \& anxiety

- Social isolation

- Reduced feelings of self-esteem

- Lower levels of social interaction

- One of the top 10 disabilities for adults (CDC, 2015) 


\section{The Role of Occupational Therapy in Vision Loss}

- Since 1917, occupational therapy practitioners (OTPs) have been involved in the rehab of individuals with low vision.

- Occupational therapy enables individuals to participate in meaningful and purposeful activities (occupations) by helping them identify successful methods for achieving performance in their daily occupations and valued life roles

- OTPs address occupational limitations as well as psychosocial factors that result from vision loss

\section{The Role of Aesthetics}

- Aesthetic techniques (i.e. grooming \& hygiene, skin care management, makeup application, hair care, \& hairstyling) are important occupations that we use every single day

- Research shows that cosmetic interventions have shown improvements in the quality of life and psychological health status of patients

- A "Look good, feel better" program helped restore appearancerelated side effects of women with cancer

- "When I looked in the mirror, I didn't see a healthy face. I saw someone who was sick. Makeup makes you feel real again, makes you feel like you're going back to the person you were before" (Kendrick, 2008). 


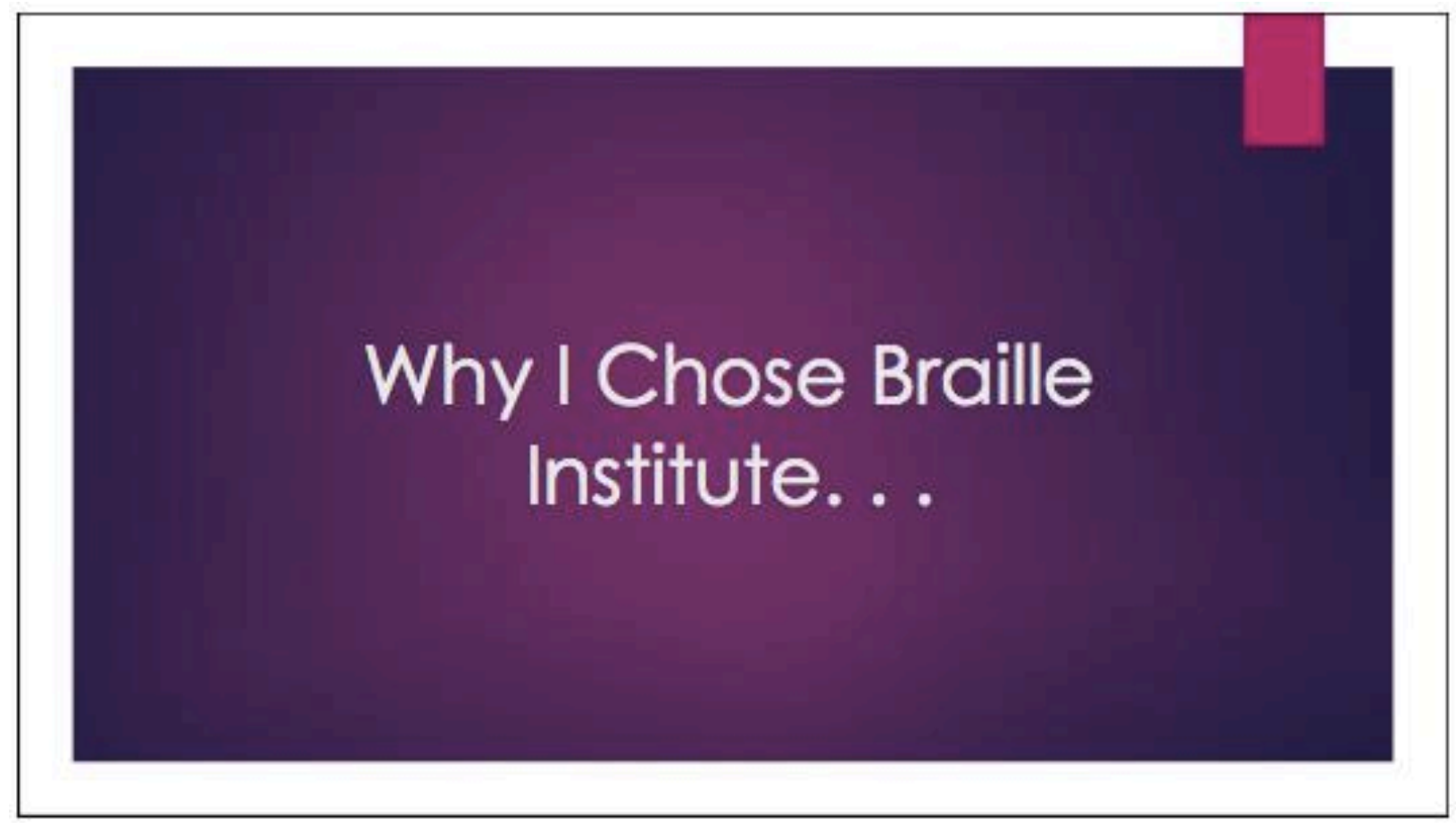

\section{Aesthetic Techniques}

\section{Program}

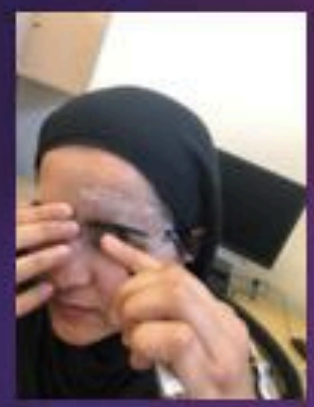

- "Skincare \& Hairstyling 101" on Mondays \& Wednesdays

- "Makeup 101" on Tuesdays \& Thursdays

- Shopping trip experience

- One-on-one sessions were offered on Monday - Thursday afternoons

- Overall participants: 22

- Started off with 11 enrolled participants, but class size grew over the course of 5 weeks 

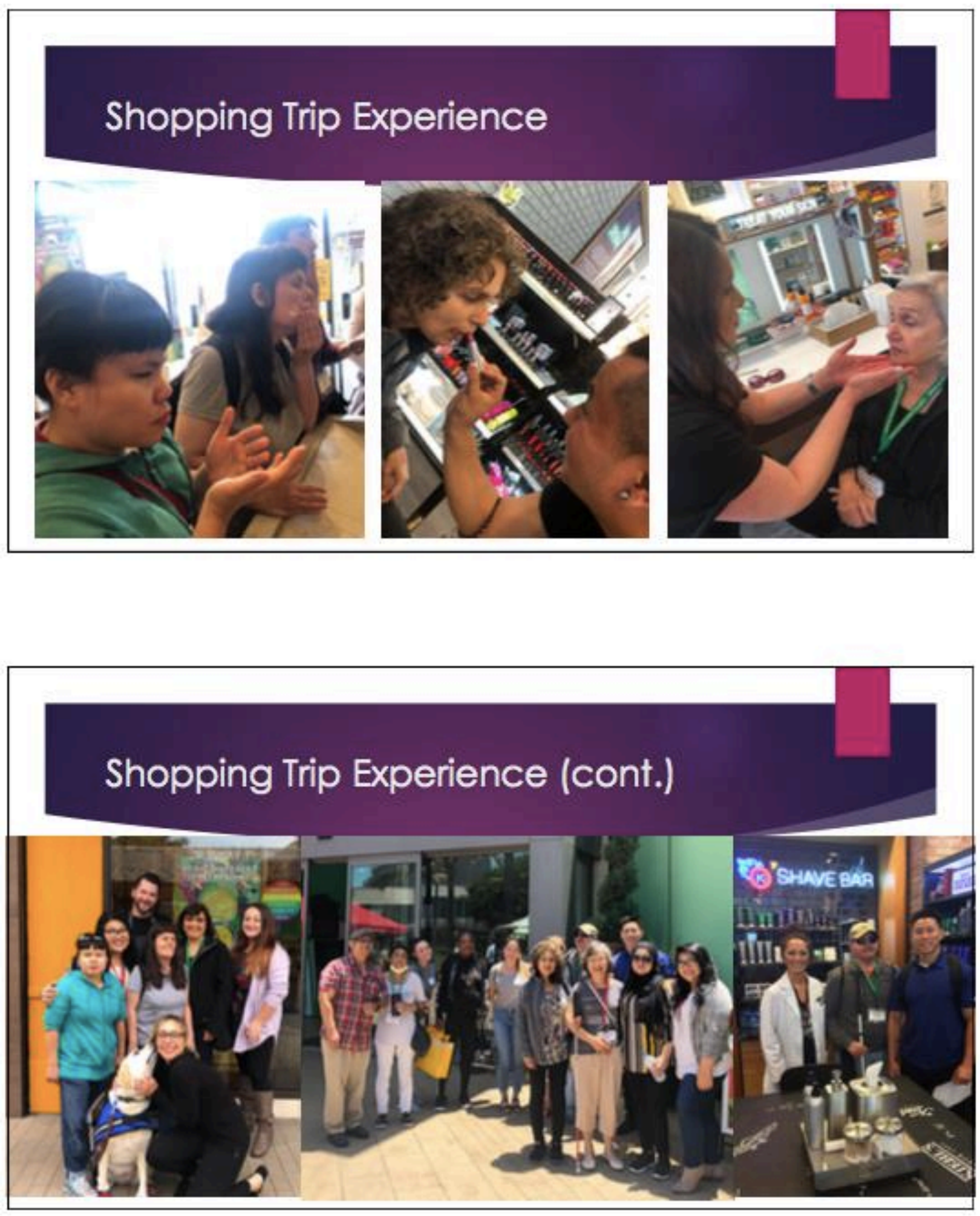


\section{Outcome Measurements}

\section{Pre \& Post Interviews}

- Consisted of quantitative \& qualitative questions

- Examined themes that pertain to self-image perception, confidence with aesthetic performance, aesthetic interests, and learned techniques

- 14 students gave consent to participate in the interviews, which provided the pre and post data.

\section{Quantitative Results}
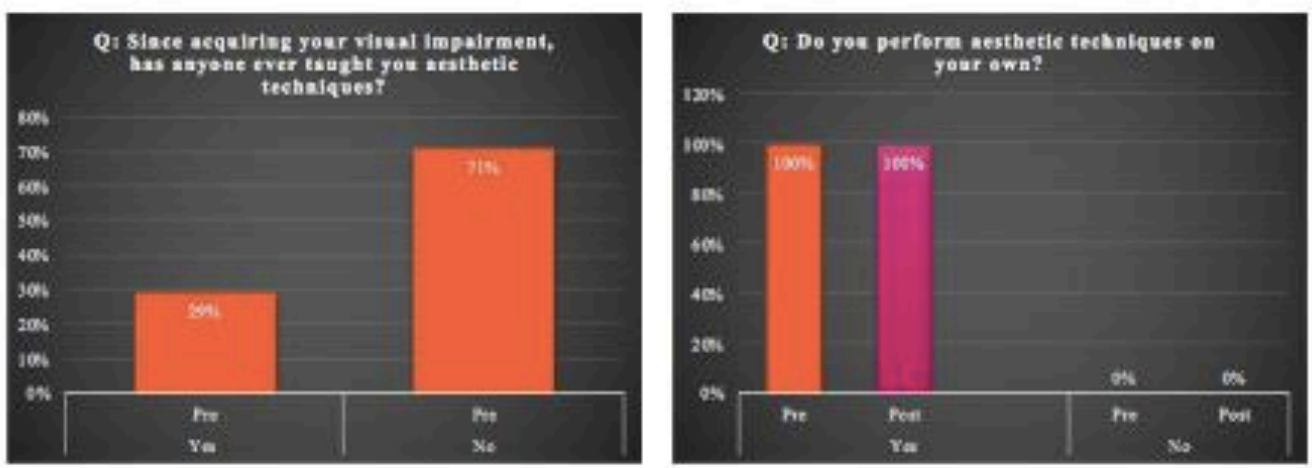


\section{Quantitative Results (cont.)}
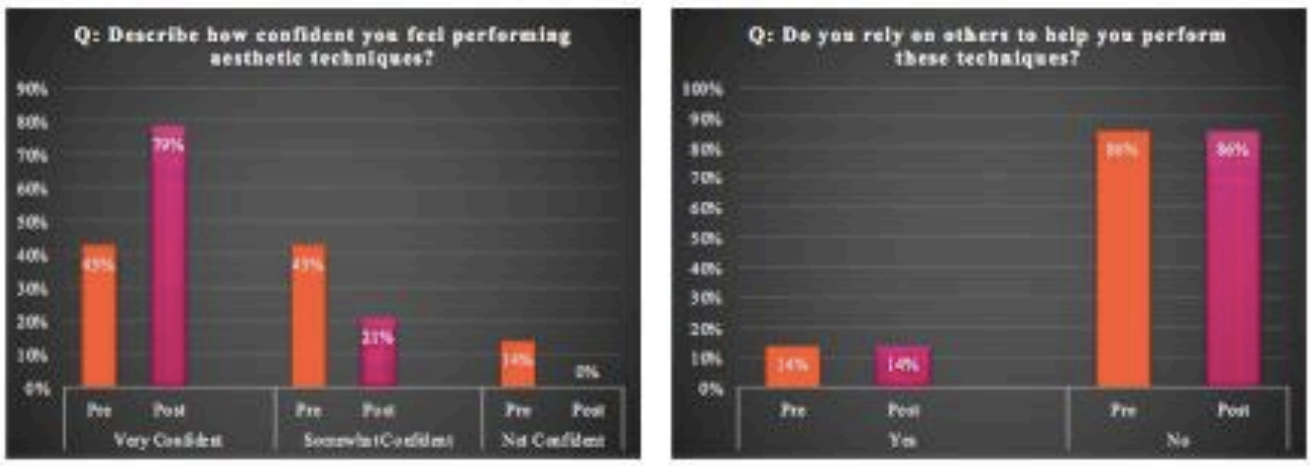

Quantitative Results (cont.)
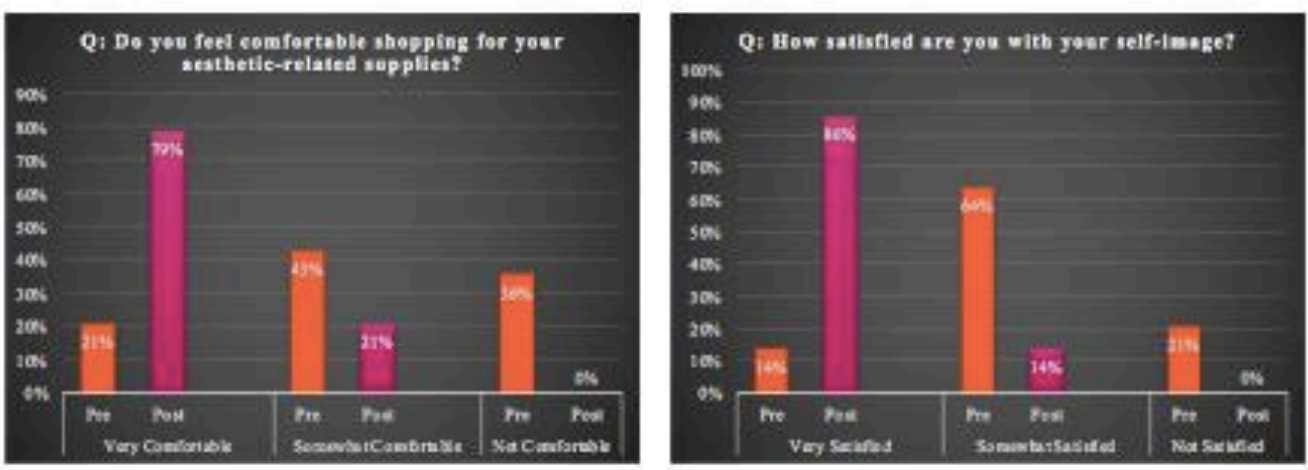


\section{Quantitative Results (cont.)}
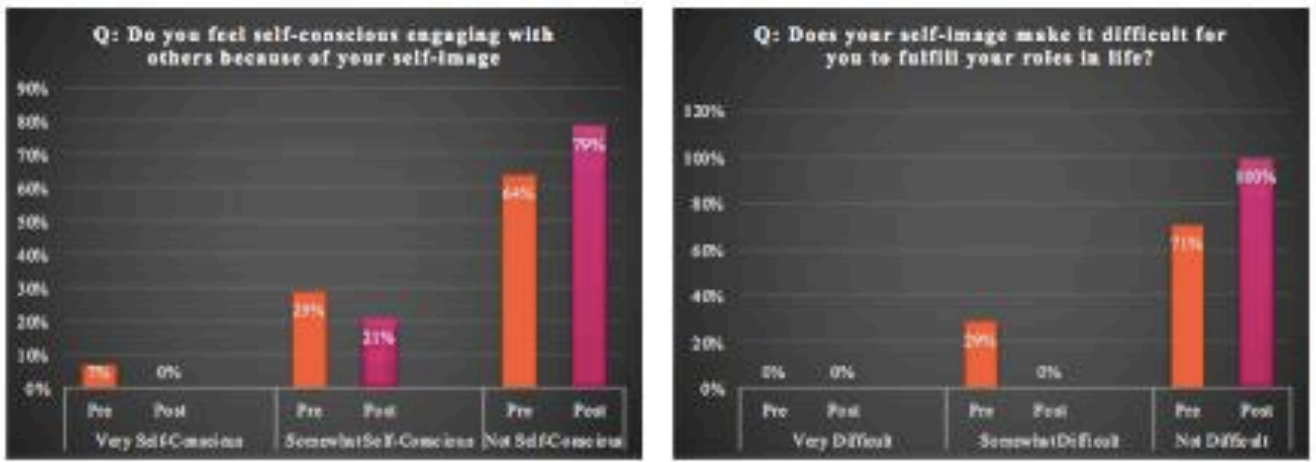

\section{Quantitative Results (cont.)}
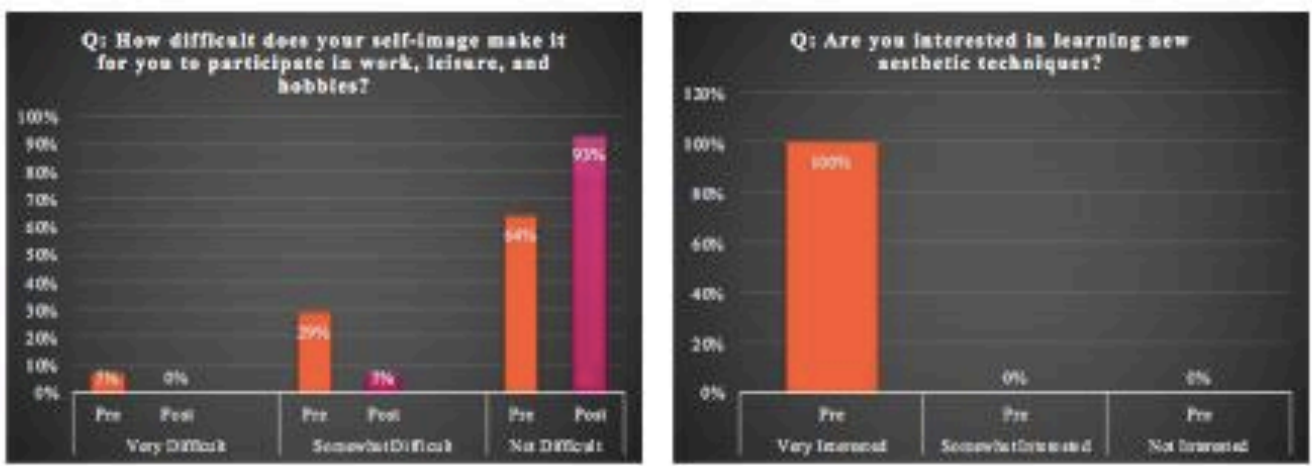


\section{Qualitative Results}

Three themes emerged from the aesthetic techniques program:

- Increased confidence and self-esteem

- The need for an aesthetic techniques program in a community of people with visual impairments

- The need to advocate for one's personal autonomy

\section{Increased Confidence \&. Self-Esteem}

- "This class impacted my life. The simple techniques you taught us about re-orienting ourselves with our face to see where our facial features are or how it may have changed has really helped me. I feel more confident when I'm putting on my makeup and doing my skin care routine. This class encourages me every day to do selfcare techniques because it's part of our self-image. My self-esteem has improved. . . I was getting depressed and had anxiety, but when I started doing something that I know is right for me, that accomplishment makes your self-esteem grow. You have given me the feeling of empowerment that I was missing." 


\section{The Need for an Aesthetic Techniques Program}

- "During my first interview at Braille, the low vision specialist back then asked me, "What is the most challenging thing to do?" I said THE most challenging thing to do was putting on my makeup. Makeup for me makes me feel good, beautiful, and confident. Being someone who was previously sighted, l've always been trained to look the best for any occasion... Dress up, wear makeup, do your hair. . . But how come no one ever taught us these things? Ever since I started taking programs for the blind, nobody has ever touched on the topics discussed in this class."

\section{The Need to Advocate for One's Personal Autonomy}

- "Not only are we learning personal care, but our families are noticing the change. For so many years, they didn't understand. Sometimes, they buy my things and I don't have a choice in what they buy. Now I know I have the choice and I can go to the store with them. The first thing I learned in this class is that I need to do something for myself. I learned many things, but that is the most important for me."

- "This class teaches us that we have the right to take care of ourselves and feel good. . This class was a reminder that "I can do this." Just because I'm blind doesn't mean I can't do this. .. " 


\section{Limitations}

Students had varying forms of visual impairments and needs. A group teaching method may be impractical for this type of class.

- Encourage students to have one-on-one time with the instructor

- 5 weeks is not enough to cover all the material.

- Based on feedback and interview responses from the students, an aesthetic-related class should be continued.

\section{Conclusion}

- The aesthetic techniques program provided students with the skills they need to increase their self-confidence, selfesteem, and performance in aesthetics.

- This program helped students gain a sense of empowerment, including being a self-advocate for their needs and their personal autonomy.

- Future projects for OTPs should include advocating to product designers, developers, and government regulators to design products with accessibility in mind. 

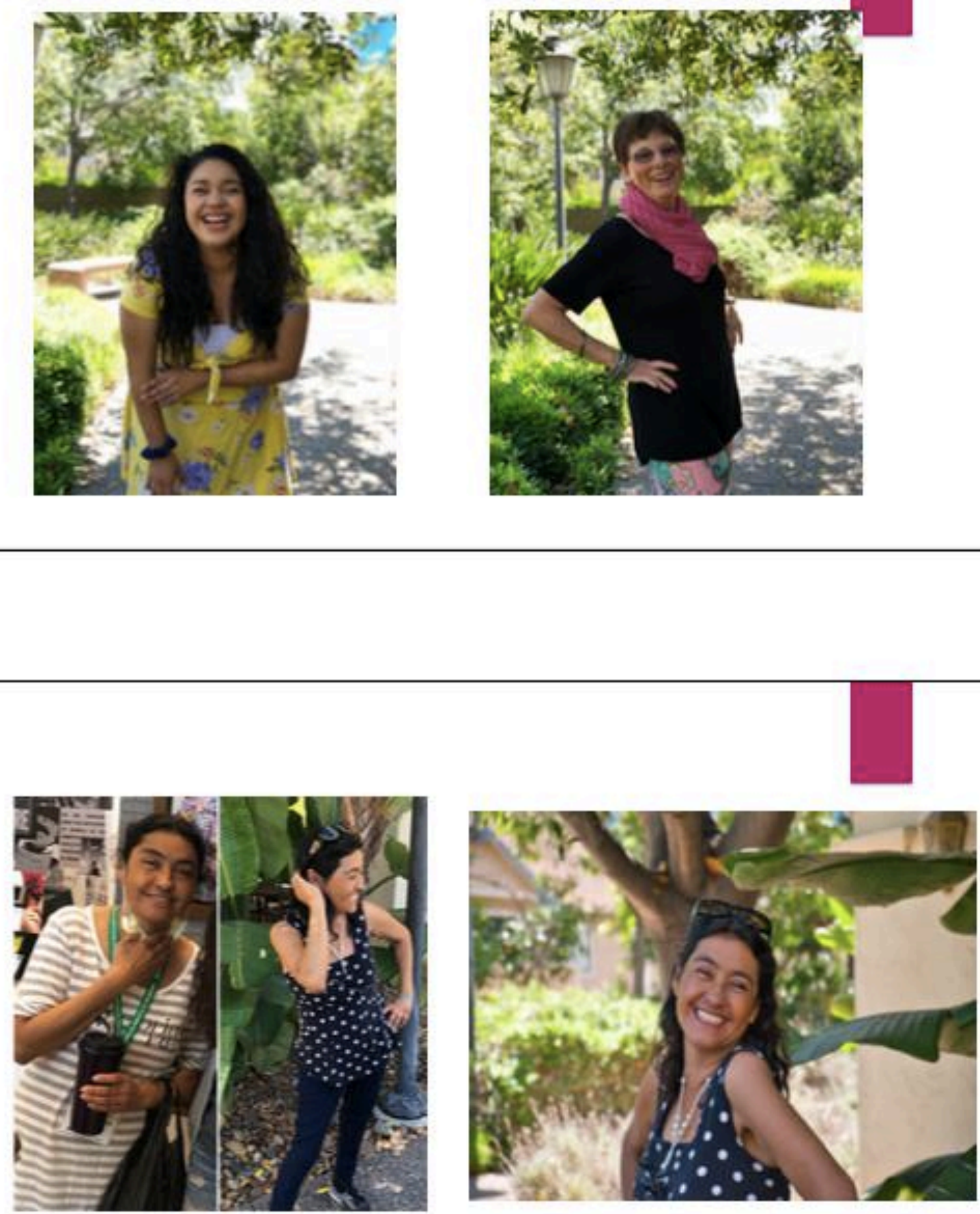

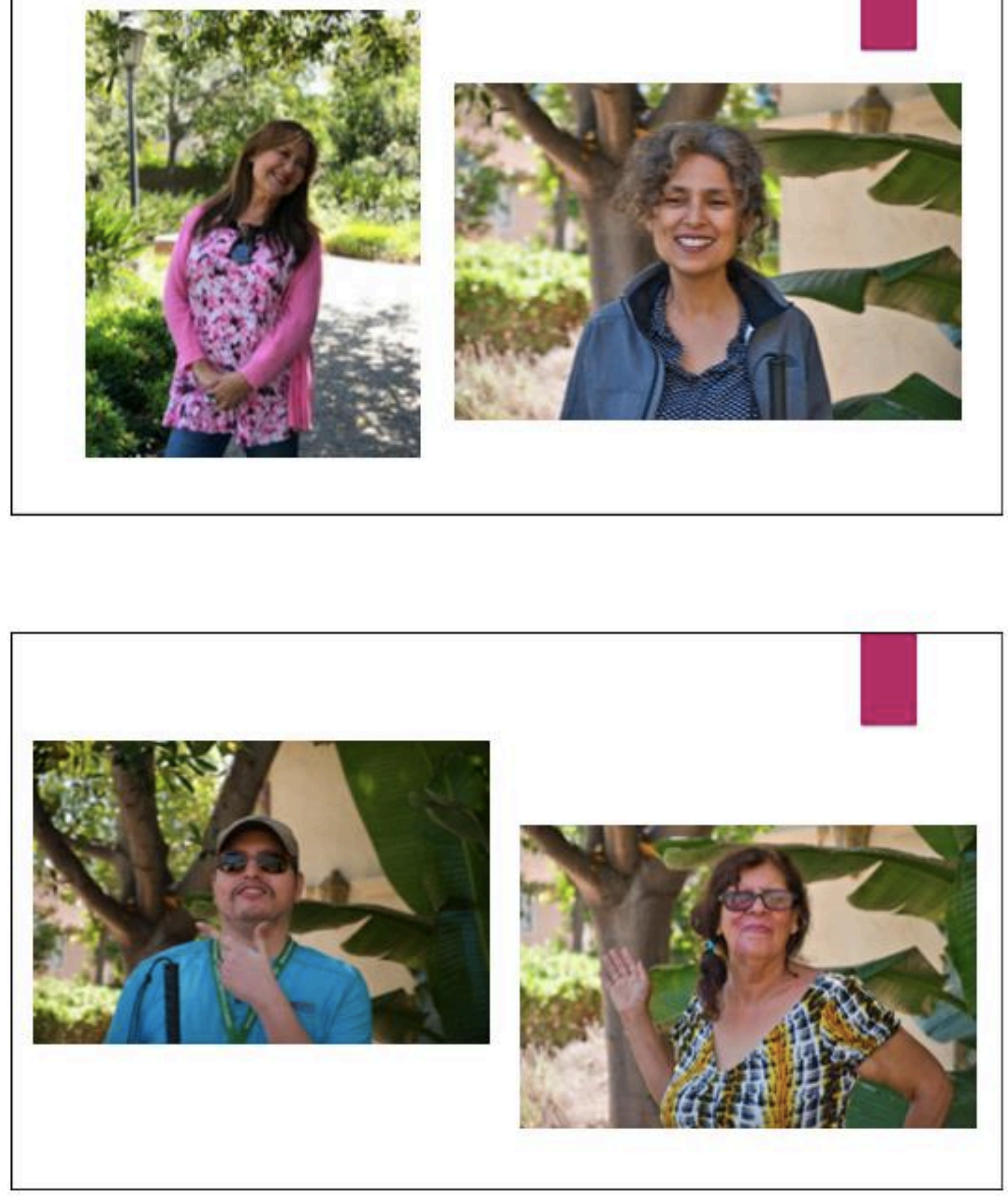

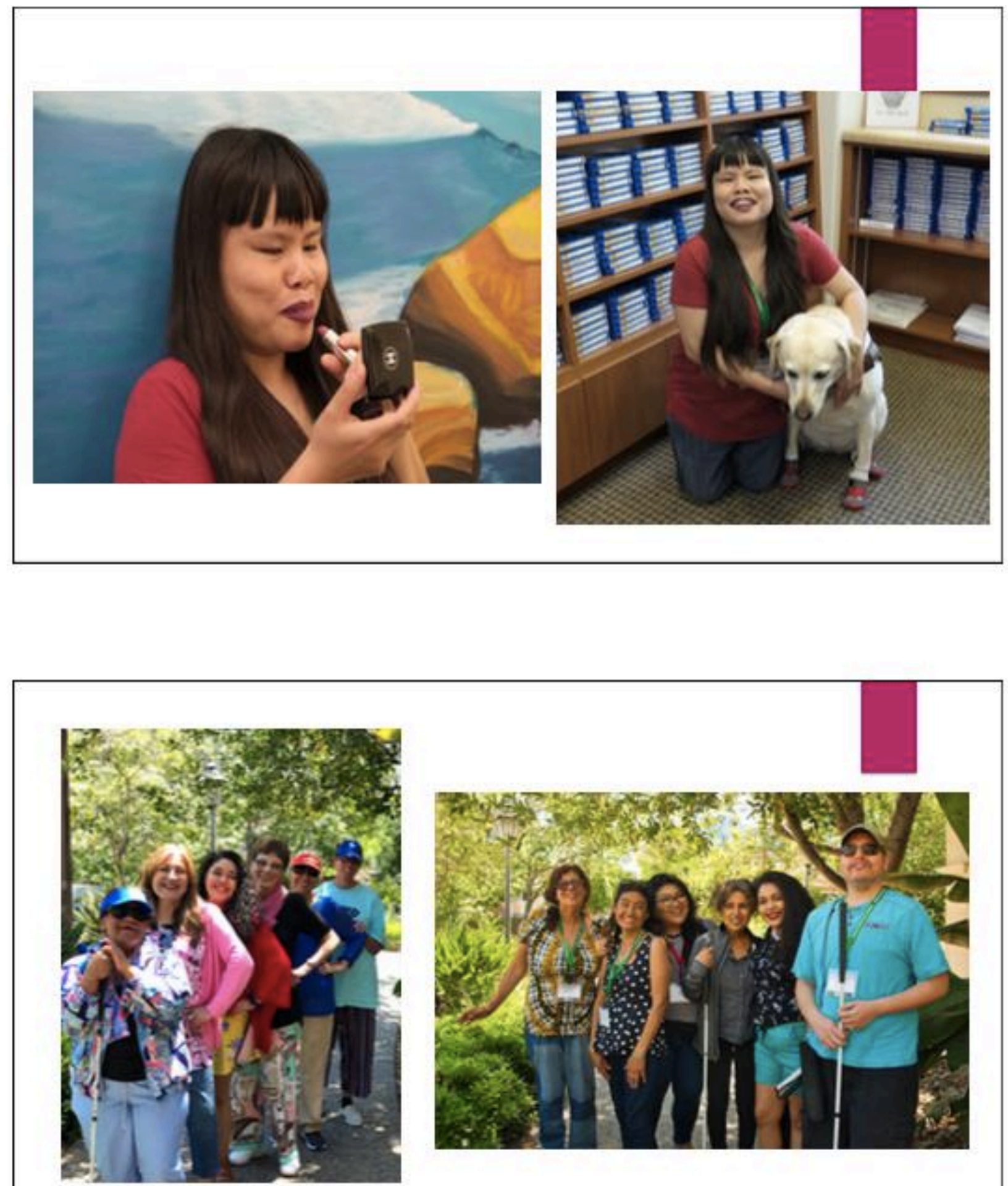


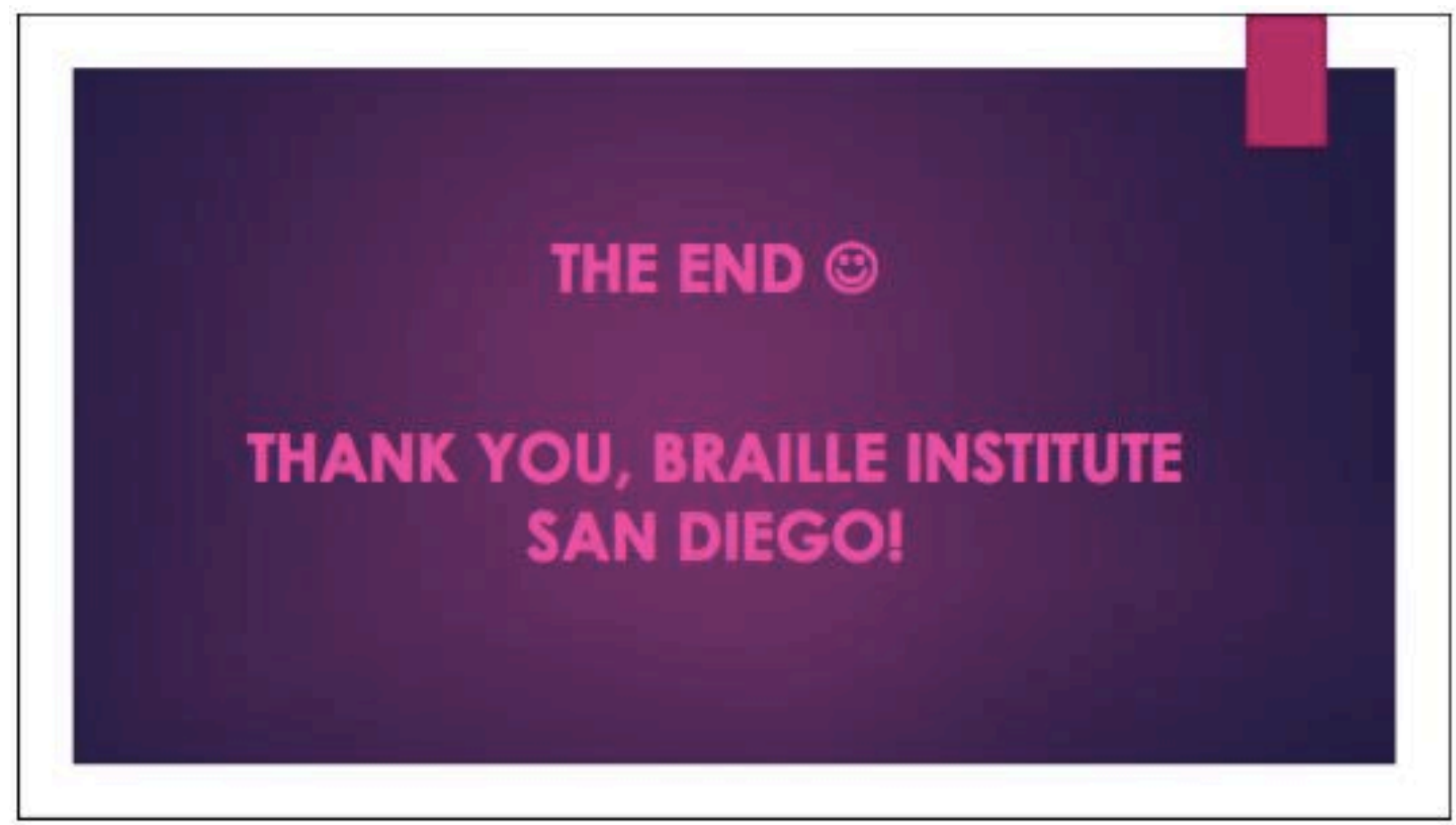

\section{References}

- Branch, L. G., Horowitz, A., \& Carr, C. (1989). The implications for everyday life of incident seff-reported visual decline among people over age 65 living in the community. Gerontologist, 29(3), 359-365.

- Centers for Disease Control and Prevention. (2015). Common Eye Disorders. Retrieved from hittos//wmwicdco.ov/visionheolth/bosics/ced/index.htm/

- Warren M. (1995). Including occupationa therapy in low vision rehabilitation. American Journd of Occupational Therapy, 49(9), 857-860. http://dx.doi. org/10.5014/ojot.49.9.857

- Kendrick, K., 2008. "Normalizing" female cancer patients: Look good, feel better and other image programs. Disability \& Society, 23(3), 259-269. http://dx.doi.org/10.1080/09687590801954042. 